\title{
Spinal Astrocyte Glutamate Receptor 1 Overexpression after Ischemic Insult Facilitates Behavioral Signs of Spasticity and Rigidity
}

\author{
Michael P. Hefferan, ${ }^{1}$ Karolina Kucharova, ${ }^{1,4}$ Kiyohiko Kinjo, ${ }^{1}$ Osamu Kakinohana, ${ }^{1}$ Gabriella Sekerkova, ${ }^{2}$ \\ Seiya Nakamura, ${ }^{1,3}$ Tatsuya Fuchigami, ${ }^{1,3}$ Zoltan Tomori, ${ }^{5}$ Tony L. Yaksh, ${ }^{1}$ Neil Kurtz, ${ }^{6}$ and Martin Marsala ${ }^{1,4}$ \\ ${ }^{1}$ Anesthesiology Research Laboratory, Department of Anesthesiology, University of California, San Diego, La Jolla, California 92093-0695, ${ }^{2}$ Department of \\ Cell and Molecular Biology, Feinberg School of Medicine, Northwestern University, Chicago, Illinois 60208, ${ }^{3}$ Department of Anesthesiology, University of \\ the Ryukyus, Okinawa, Japan 903-0213, Institutes of ${ }^{4}$ Neurobiology and ${ }^{5}$ Experimental Physics, Slovak Academy of Sciences, 04001 Kosice, Slovakia, and \\ ${ }^{6}$ TorreyPines Therapeutics, La Jolla, California 92037
}

Using a rat model of ischemic paraplegia, we examined the expression of spinal AMPA receptors and their role in mediating spasticity and rigidity. Spinal ischemia was induced by transient occlusion of the descending aorta combined with systemic hypotension. Spasticity/ rigidity were identified by simultaneous measurements of peripheral muscle resistance (PMR) and electromyography (EMG) before and during ankle flexion. In addition, Hoffman reflex (H-reflex) and motor evoked potentials (MEPs) were recorded from the gastrocnemius muscle. Animals were implanted with intrathecal catheters for drug delivery and injected with the AMPA receptor antagonist NGX424 (tezampanel), glutamate receptor 1 (GluR1) antisense, or vehicle. Where intrathecal vehicle had no effect, intrathecal NGX424 produced a dose-dependent suppression of PMR [ $\mathrm{ED}_{50}$ of $\left.0.44 \mu \mathrm{g}(0.33-0.58)\right]$, as well as tonic and ankle flexion-evoked EMG activity. Similar suppression of MEP and H-reflex were also seen. Western blot analyses of lumbar spinal cord tissue from spastic animals showed a significant increase in GluR1 but decreased GluR2 and GluR4 proteins. Confocal and electron microscopic analyses of spinal cord sections from spastic animals revealed increased GluR1 immunoreactivity in reactive astrocytes. Selective GluR1 knockdown by intrathecal antisense treatment resulted in a potent reduction of spasticiy and rigidity and concurrent downregulation of neuronal/astrocytic GluR1 in the lumbar spinal cord. Treatment of rat astrocyte cultures with AMPA led to dose-dependent glutamate release, an effect blocked by NGX424. These data suggest that an AMPA/kainate receptor antagonist can represent a novel therapy in modulating spasticity/rigidity of spinal origin and that astrocytes may be a potential target for such treatment.

Key words: ischemia; spinal cord injury; astrocytes; AMPA receptor; spasticity; rigidity

\section{Introduction}

Spasticity is defined as muscle hypertonia exhibiting increased muscle resistance to an externally imposed movement when the muscle is stretched rapidly above a threshold speed or angle of rotation (Lance et al., 1970; Sanger et al., 2003). Rigidity is continuous involuntary muscle contraction: the degree of resistance remains constant regardless of the rate at which the muscle is stretched (Maurice et al., 2001). Several pathological conditions can lead to spasticity/rigidity, such as ischemic or traumatic spinal cord injury, brain trauma, multiple sclerosis, cerebral palsy, or Parkinson's disease (Dabney et al., 1997; Dietz, 2001; Beard et

Received Jan. 24, 2006; revised June 27, 2007; accepted June 28, 2007.

This work was supported by National Institutes of Health Grant NS 40386 (M.M.), Grantom vedeckej grantouej agentury Grant 5048 (Z.T.), and American Heart Association Postdoctoral Fellowship 0425085 Y (M.P.H.). N.K. is President and CEO of TorreyPines Therapeutics (La Jolla, CA) and has a financial interest in the company. A portion of the expenses for these studies was funded by TorreyPines Therapeutics.

Correspondence should be addressed to Dr. Michael P. Hefferan, Anesthesiology Research Laboratory, Department of Anesthesiology, University of California, San Diego, 9500 Gilman Drive, La Jolla, CA 92093-0695. E-mail: mhefferan@ucsd.edu.

D0I:10.1523/JNEUROSCI.0989-07.2007

Copyright $\odot 2007$ Society for Neuroscience $\quad$ 0270-6474/07/2711179-13\$15.00/0 al., 2003). Although diverse in etiology, these conditions have a common denominator: they lead to increased peripheral muscle tone secondary to enhanced $\alpha$-motoneuron activity. Until recently, the most commonly described mechanisms thought to contribute to exaggerated motor cell activity include the following: (1) increased primary Ia afferent activity, probably a result of decreased presynaptic inhibition (Tarlov, 1967; Matsushita and Smith, 1970; Mailis and Ashby, 1990; Faist et al., 1994; SalazarTorres Jde et al., 2004); (2) loss of descending inhibition (Taylor et al., 1999); (3) loss of segmental inhibitory interneurons (Tarlov, 1967; Matsushita and Smith, 1970; Taira and Marsala, 1996); and/or (4) loss of recurrent inhibition mediated by Renshaw cells (Mazzocchio and Rossi, 1989). For a broad review, see Sheean (2002) and Ivanhoe and Reistetter (2004).

Although these proposed mechanisms focus on neuronal elements, it is now well appreciated that glial cells can be actively involved in some neurological disease states in which they are thought to facilitate pathological signal processing through a variety of means, such as altered expression of plasma membrane receptors/ion channels/transporters and production of several cytokines and chemokines (Seifert et al., 2004, 2006; Matsui et al., 
2005; Tawfik et al., 2007). Injury to the CNS triggers glial activation, and it appears that activated astrocytes can engage in bidirectional communication with neighboring neurons, resulting for example in increased intracellular $\mathrm{Ca}^{2+}$ concentration and glia transmitter release (Zhang et al., 2003). Pathology-induced changes in astrocytic AMPA receptor expression have been implicated in the evolution and/or maintenance of some neurological disorders. For example, increased glutamate receptor 4 (GluR4) expression was found in white matter astrocytes after traumatic spinal cord injury (Agrawal and Fehlings, 1997), and astrocytic GluR1-immunoreactivity (IR) was increased in the CA1 hippocampal region after transient forebrain ischemia (Gottlieb and Matute, 1997). Tian et al. (2005) suggested that astrocytes play a key role in epileptic seizures in which glial cells are thought to release glutamate and trigger paroxysmal depolarization shifts in nearby neurons (Tian et al., 2005). Studying hippocampal tissue from epileptic patients, Seifert et al. (2004) theorized that glutamate activates astrocytic AMPA receptors, prolonging astrocyte depolarization and facilitating the generation and/or spread of seizure activity (Seifert et al., 2004).

Using a rat model of spinal ischemic paraplegia (Taira and Marsala, 1996; Marsala et al., 2005), the present study characterized (1) changes in spinal AMPA receptor subunit expression after spinal cord ischemia and (2) effects of spinal AMPA/ kainate (KA) receptor blockade or GluR1 antisense treatment on spasticity/rigidity.

\section{Materials and Methods}

All procedures were approved by the Animal Care Committee at the University of California, San Diego.

Animals. Male Sprague Dawley rats (300-350 g) were obtained from Harlan (Indianapolis, IN) and were housed in standard cages with corncob bedding. Animals had access to food and water ad libitum and were housed separately after surgery. A $12 \mathrm{~h}$ light/dark cycle (lights on at 7:00 A.M.) was used throughout.

Induction of spinal ischemic spasticity and rigidity. Spinal ischemia was induced using the previously described technique (Taira and Marsala, 1996). Briefly, rats were anesthetized with $4 \%$ isoflurane in air and maintained with $1.5-2 \%$ isoflurane; body temperature was maintained at $37^{\circ} \mathrm{C}$ using a homeothermic blanket system. Distal arterial blood pressure and heart rate were monitored by a tail artery catheter. The left carotid artery was cannulated with a 20 gauge polytetrafluoroethylene catheter for blood withdrawal. To induce spinal ischemia, a 2F Fogarty catheter (Am. V. Mueller, CV 1035; Baxter, Irvine, $\mathrm{CA}$ ) was passed through the left femoral artery to the descending thoracic aorta so that the tip reached the level of the left subclavian artery (10.8$11.4 \mathrm{~cm}$ from site of insertion). The intra-aortic balloon catheter was inflated with $0.05 \mathrm{ml}$ of saline, and occlusion of aortic blood flow was confirmed by an immediate and sustained drop in distal arterial blood
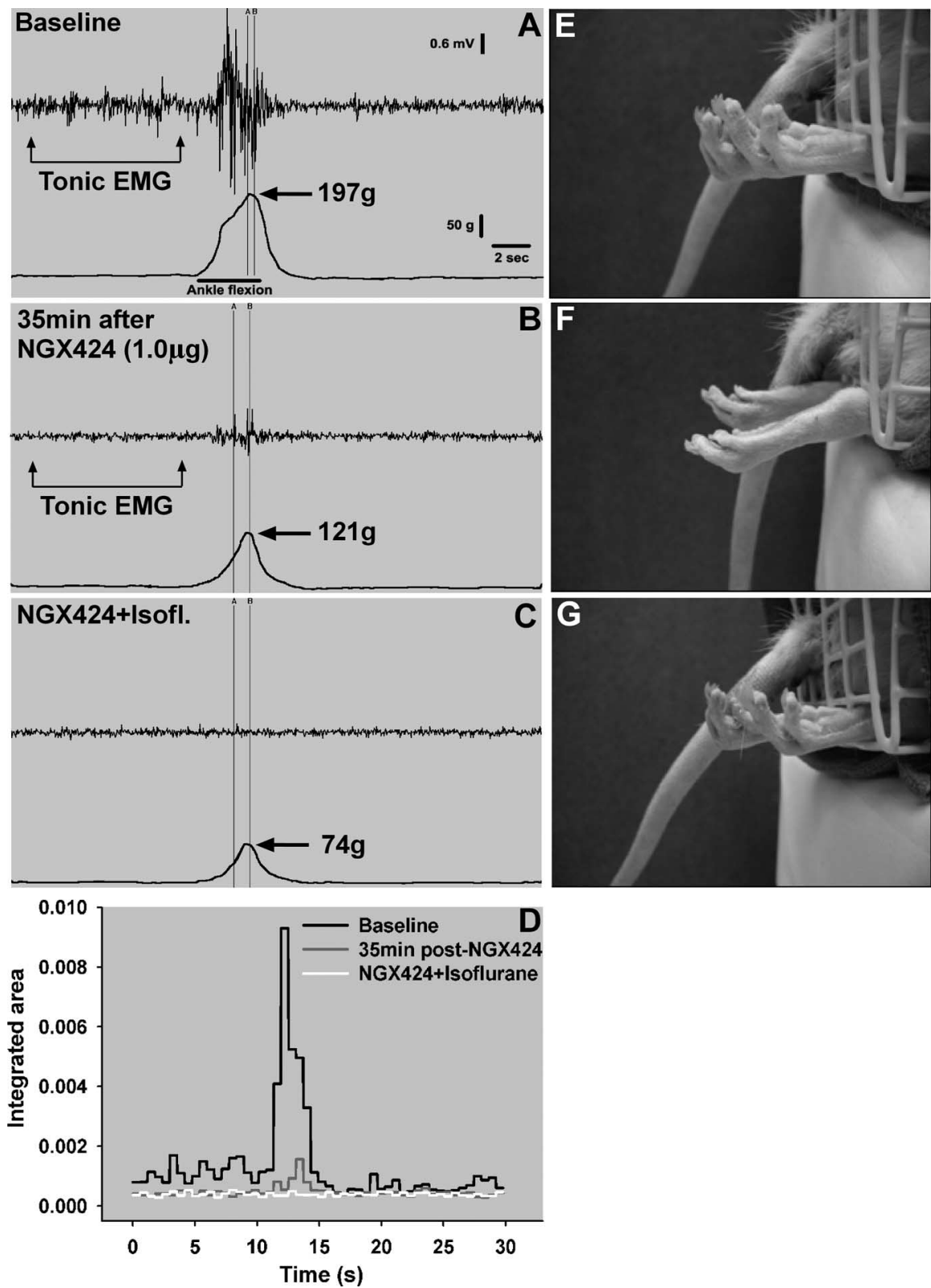

Figure 1. Concurrent EMG and PMR recording in a rat 3 weeks after spinal ischemia is attenuated after intrathecal NGX424. $\boldsymbol{A}$, EMG and PMR recorded in a spastic rat shows both tonic and flexion-evoked EMG activity and significant increase in PMR during ankle flexion. $\boldsymbol{B}$, Intrathecal injection of NGX424 (1.0 $\mu \mathrm{g})$ attenuated both EMG (tonic and evoked) and PMR. C, Addition of isoflurane anesthesia (2\%) further reduced EMG and PMR. D, Integration analysis of the EMG data illustrates the efficacy of before intrathecal injection of NGX424 (1.0 $\mu \mathrm{g})$ showing intense dorsal-plantar and digit flexion. $\boldsymbol{F}$, $\boldsymbol{G}$, Thirty-five minutes after injection $(\boldsymbol{F})$, flexion was no longer present but reappeared by $24 \mathrm{~h}$ after drug administration $(\boldsymbol{G})$.

pressure. Systemic hypotension $(40 \mathrm{mmHg}$ ) was maintained during occlusion by a blood collecting circuit $\left(37.5^{\circ} \mathrm{C}\right)$ connected to the carotid artery and positioned at the height of $54 \mathrm{~cm}(40 \mathrm{mmHg})$. After ischemia, the balloon was deflated, and the blood was reinfused during a $60 \mathrm{~s}$ period. After blood reinfusion, $4 \mathrm{mg}$ of protamine sulfate was administered subcutaneously. Stabilization of arterial blood pressure was then monitored for an additional $10 \mathrm{~min}$, after which the arterial lines were removed and wounds were closed. Rats were then allowed to recover. Seven to $10 \mathrm{~d}$ after ischemia, animals were tested for the presence of spasticity and rigidity. Rigidity was identified by the presence of ongoing tonic electromyographic (EMG) activity measured in gastrocnemius muscle as well as continuous dorsal plantar flexion of paw digits. Spasticity was identified as an increase in muscle resistance during ankle rotation, which 

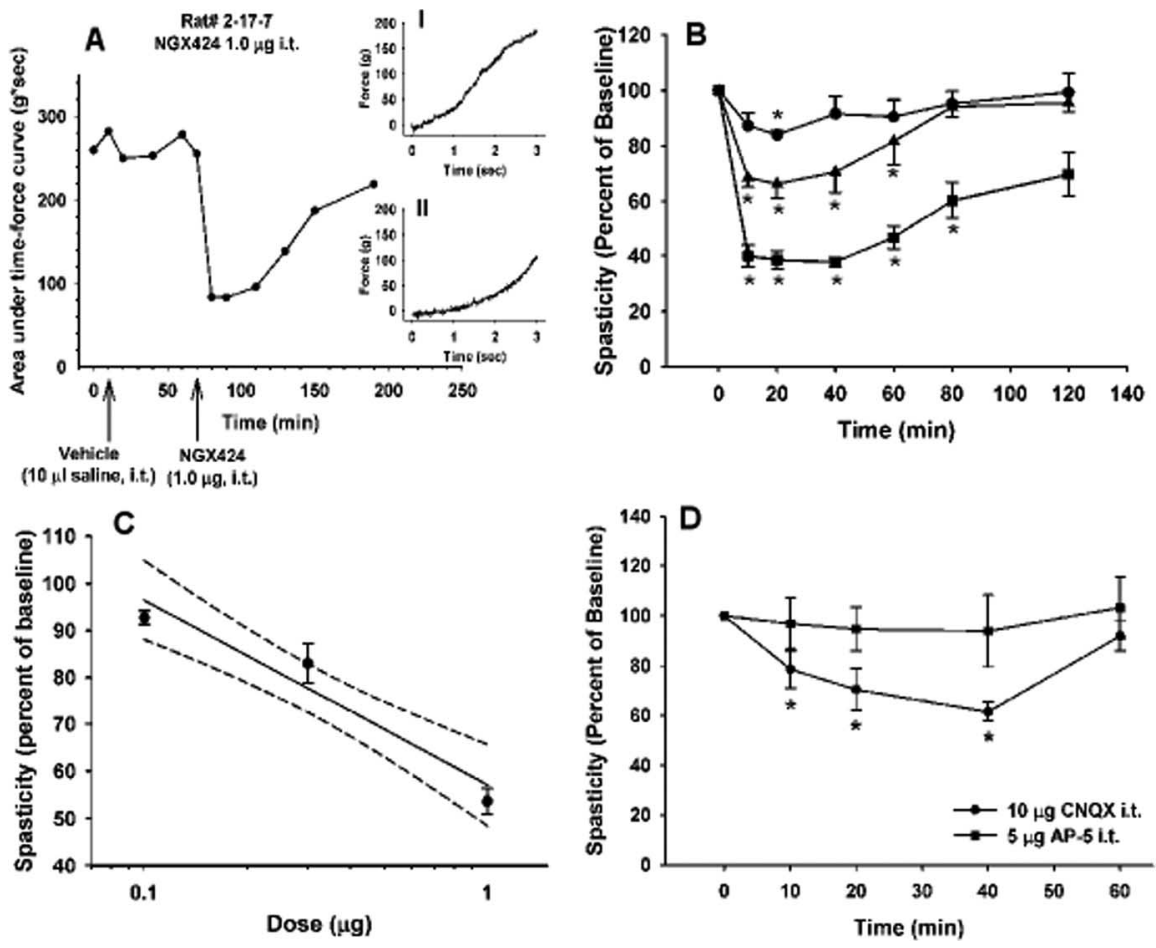

Figure 2. Intrathecal NGX424 temporarily reduces behavioral spasticity. $\boldsymbol{A}$, Representative experiment demonstrating the anti-spastic effect of intrathecal NGX424 in a single animal. Inset I depicts a single muscle resistance measurement during ankle rotation before NGX424 treatment; inset II shows significant reduction in measured resistance 20 min after intrathecal NGX424 $(1.0 \mu \mathrm{g})$. $\boldsymbol{B}$, Time courses for three intrathecal doses of NGX424:, $0.1 \mu \mathrm{g} ; \boldsymbol{\Delta}, 0.3 \mu \mathrm{g} ; \boldsymbol{\square}, 1.0 \mu \mathrm{g} . n=5$ animals per dose. $\boldsymbol{C}$, Solid line shows the dose-response curve for NGX424 with an $\mathrm{ED}_{50}$ of $0.44 \mu \mathrm{g}$. Dashed lines indicate the $95 \%$ confidence intervals. D, Time course for a single intrathecal dose of CNQX $(10 \mu \mathrm{g})$ or AP-5 $(5 \mu \mathrm{g}) ; n=4-5$ animals. For $\boldsymbol{A}-\boldsymbol{D}$, each point represents the mean \pm SEM; drug-induced changes in peripheral muscle resistance are expressed as percentage baseline resistance (i.e., before drug injection; see Materials and Methods).

correlated with increased EMG activity measured in gastrocnemius muscle during the same time fame (see details below).

Intrathecal catheterization. At 14-21 d after spinal cord ischemia, intrathecal catheters were implanted as described previously (Yaksh and Rudy, 1976; Hefferan et al., 2003). Under isoflurane anesthesia, an $8.5 \mathrm{~cm}$ catheter (polyethylene-5 connected to $\sim 4 \mathrm{~cm}$ of polyehtylene-10 for externalization) was inserted through an incision in the atlanto-occipital membrane of the cisterna magna. The catheter was externalized behind the head and sealed with a piece of stainless steel wire. Rats exhibiting normal forelimb gait, feeding, and grooming behavior were housed separately and allowed to recover for at least $4 \mathrm{~d}$ before drug treatment.

Peripheral muscle resistance measurement. Direct measurement of hindlimb muscle resistance was performed as described previously (Marsala et al., 2005). Briefly, rats were individually placed in a plastic restrainer, and one hindpaw was securely fastened to the paw attachment metal plate, which is interconnected loosely to the "bridging" force transducer (LCL454G, 0-454 g range; or LCL816G, 0-816 g range; Omega, Stamford, CT). After a $20 \mathrm{~min}$ acclimation period, rotational force was applied to the paw attachment unit using a computer-controlled stepping motor (MDrive 34 with onboard electronics; microstep resolution to 256 microsteps/full step; Intelligent Motion Systems, Marlborough, CT), causing the ankle to flex. The resistance of the ankle to flexion was measured during $40^{\circ}$ of rotation during $3 \mathrm{~s}(13.3 \% \mathrm{~s})$, and data were collected directly to a computer using custom software (Spasticity version 2.01; Ellipse, Kosice, Slovak Republic). Each recorded value was the average of three repetitions.

EMG recordings. To record EMG activity, a pair of tungsten electrodes were inserted percutaneously into the gastrocnemius muscle $1 \mathrm{~cm}$ apart. EMG signals were bandpass filtered $(100 \mathrm{~Hz}$ to $10 \mathrm{kHz})$ and recorded before, during, and after ankle flexion. EMG responses were recorded with an alternating current-coupled differential amplifier (model DB4;
World Precision Instruments, Sarasota, FL) and stored on a computer for subsequent analysis. EMG was recorded concurrently with peripheral muscle resistance (PMR), and therefore data were recorded as the average of three measurements.

Evaluation of drug treatment on whisker/corneal reflex. Because of the paraplegic phenotype after spinal ischemia, routine testing for druginduced motor deficit (e.g., rotorod) is impractical. Therefore, only the supraspinally mediated whisker and corneal reflexes were tested in spastic rats: a cotton-tipped applicator was used to gently displace the whiskers or touch the outer edge of the eye while monitoring reactions. Responses were graded as follows: 0 , normal; 1, mildly impaired; 2, consistently impaired (rarely present); 3, absent. Effects on normal motor activity were assessed in naive rats in an open-field paradigm.

Recording of motor evoked potentials. Motor evoked potentials (MEPs) were recorded using a previously described technique (Kakinohana et al., 2006). Briefly, animals were anesthetized and maintained with ketamine $\left(100 \mathrm{mg} \cdot \mathrm{kg}^{-1} \cdot \mathrm{h}^{-1}\right.$, i.m.). MEPs were elicited by transcranial electrical stimulation $(20 \mathrm{~V}, 200 \mathrm{~ms})$ of the motor cortex using percutaneously placed stainless steel stimulating electrodes on each side of the skull slightly lateral of midline in a rostrocaudal direction. Responses were recorded from the gastrocnemius muscle using silver needle (22 gauge) electrodes (distance between recording electrodes, $1 \mathrm{~cm}$ ) and a differential amplifier (model DB4; World Precision Instruments) and digitized with custom software (EP 2001; Dr. Jan Galik, Institute of Neurobiology, Kosice, Slovak Republic). For each data point, 10 repetitions were averaged and stored.

Hoffman reflex recording. Hoffman reflex $(\mathrm{H}-$ reflex) was recorded as previously described (Schwarz et al., 1994; Kakinohana et al., 2006). Briefly, under ketamine anesthesia $\left(100 \mathrm{mg} \cdot \mathrm{kg}^{-1} \cdot \mathrm{h}^{-1}, \mathrm{i} . \mathrm{m}\right.$.) the right hindlimb of the animal was secured, and a pair of stimulating needle electrodes was transcutaneously inserted into the surroundings of the tibial nerve. For recording, a pair of silver needle electrodes was placed into the interosseous muscles between the fourth and the fifth or the first and the second metatarsal right foot muscles. The tibial nerve was stimulated using square pulses with increasing stimulus intensity $(0.1-10 \mathrm{~mA}$ in $0.5 \mathrm{~mA}$ increments, 0.1 $\mathrm{Hz}, 0.2$ ms; Isostim A320; World Precision Instruments), and responses were recorded with an alternating current-coupled differential amplifier (model DB4; World Precision Instruments). The threshold for both the $\mathrm{M}$ and $\mathrm{H}$ waves was determined, and the $\mathrm{H}_{\max } / \mathrm{M}_{\max }$ ratio was calculated.

Intrathecal drug delivery and data collection. For intrathecal drug injection, the externalized portion of the intrathecal catheter was attached to a hand-operated microinjector through an opening on the side of the rat restrainer. NGX424 (tezampanel) (generous gift from TorreyPines Therapeutics, La Jolla, CA), 6-cyano-7-nitroquinoxaline-2,3-dione (CNQX) (Sigma, St. Louis, MO), or DL-2-amino-5-phosphonopentanoic acid (AP-5) (Sigma) were dissolved in $0.9 \%$ sterile saline and delivered in a volume of $10 \mu \mathrm{l}$, followed by $10 \mu \mathrm{l}$ of sterile saline flush. All equipment was sterilized with $70 \%$ alcohol before injection and thoroughly rinsed with $0.9 \%$ sterile saline. After injection, the intrathecal catheter was immediately resealed with the stainless steel plug. Measurements were taken before drug administration, followed by identical measurements taken every 10-20 min for up to $3 \mathrm{~h}$ after drug treatment.

GluR1 antisense oligodeoxynucleotide design and treatment. Oligodeoxynucleotides (19 bases in length) were synthesized (Operon, Huntsville, AL) based on the GluR1 cDNA (GenBank accession number NM031608) listed in www.ncbi.nlm.nih.gov. The specific antisense oligonucleotide $\left(5^{\prime}-\mathrm{T}^{\star} \mathrm{A}^{\star} \mathrm{A}^{\star} \mathrm{GCATCACGTAAGG}{ }^{\star} \mathrm{A}^{\star} \mathrm{T}^{\star} \mathrm{C}-3^{\prime}\right.$; phosphoro- 
Table 1. Reflex scores after intrathecal NGX424

\begin{tabular}{llllll}
\hline NGX424 dose $(\mu \mathrm{g})$ & 0.1 & 0.3 & 1.0 & 3.0 & 30.0 \\
\hline Reflex score & $0.00 \pm 0.00$ & $0.00 \pm 0.00$ & $0.00 \pm 0.00$ & $0.33 \pm 0.21$ & $1.67 \pm 0.17$ \\
\hline Supraspina & $2.67 \pm 0.22$ \\
\hline
\end{tabular}

Supraspinal effects of intrathecal NGX424 were monitored by checking corneal and whisker reflexes. Doses of $1.0 \mu \mathrm{g}$ or less appeared to have no effect on alertness, whereas higher doses seemed to have mild to severe sedative effects that are positively correlated with dose.
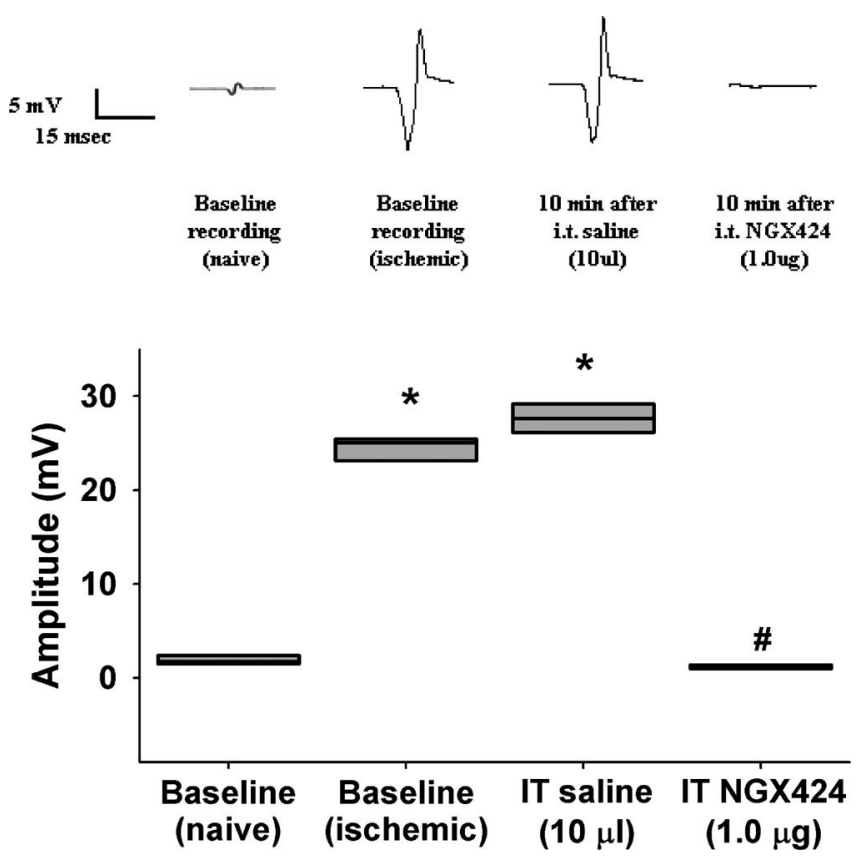

Figure 3. Transient spinal cord ischemia results in exaggerated MEPs, which are pharmacologically blocked with intrathecal NGX424. Top tracings show a representative experiment demonstrating the effect of spinal ischemia on MEPs recorded 3 weeks after reflow and the effect of intrathecal saline or NGX424 on the injury-induced increase in MEPs. The bottom is pooled MEP amplitude data from four separate animals. The upper and lower limits of each box represent the 75th and 25th percentiles, respectively, and the horizontal line within each box is the population median. ${ }^{*}$ indicates significant difference from baseline (naive) but no difference between each *; \# indicates significant difference from baseline (ischemic) and the intrathecal saline group but no difference from baseline (naive).

thiate-DNA chimera) was complementary to positions $1249-1268$ of rat GluR1 cDNA. A missense ("scrambled") antisense, for use as a control, was also prepared in which the bases of the GluR1 oligonucleotide were randomized $\left(5^{\prime}-A^{\star} G^{*} C^{\star} G T A T C A C A G T A T A * G^{\star} A^{\star} C-3^{\prime}\right.$; phosphorothiate-DNA chimera). This control sequence revealed no other rodent sequence homology using the BLAST (basic local alignment search tool) search. In previous in vitro studies, we demonstrated that treatment of cortical or spinal primary cultures with short hairpin RNA targeting the same GluR1 sequence effectively downregulated neuronal and astrocytic GluR1 expression (Kinjoh et al., 2005).

To study the specific effects of GluR1 knockdown, ischemic-spastic rats were implanted with intrathecal catheters. At $4-5 \mathrm{~d}$ after implantation, baseline hindlimb muscle resistance and gastrocnemius EMG activity were recorded. Antisense or missense oligonucleotides $(50 \mu \mathrm{g})$ were then injected intrathecally daily for $5 \mathrm{~d}$. After $5 \mathrm{~d}$ of injections, muscle resistance and EMG activity were again recorded. At the end of recording, animals were deeply anesthetized with pentobarbital $(100 \mathrm{mg} / \mathrm{kg}$, i.p.) and phenytoin ( $25 \mathrm{mg} / \mathrm{kg}$, i.p.) and prepared for immunohistochemistry (see below).

Western blotting. Rats were deeply anesthetized with pentobarbital $(100 \mathrm{mg} / \mathrm{kg}$, i.p.) and phenytoin $(25 \mathrm{mg} / \mathrm{kg}$, i.p.), and spinal cords were rapidly removed by hydroextrusion and homogenized by sonication in lysis buffer [ $50 \mathrm{~mm}$ Tris- $\mathrm{HCl}$, pH 8.0, with $1 \mathrm{~mm}$ EDTA, $150 \mathrm{~mm} \mathrm{NaCl}$, $1 \%$ NP-40, 0.5\% deoxycholic acid, $0.5 \%$ saponin, and $0.1 \%$ SDS with phosphatase and protease inhibitor cocktails (Sigma)]. After centrifugation of homogenates $\left(14,000 \mathrm{rpm}\right.$ at $\left.4^{\circ} \mathrm{C}, 15 \mathrm{~min}\right)$, supernatants were
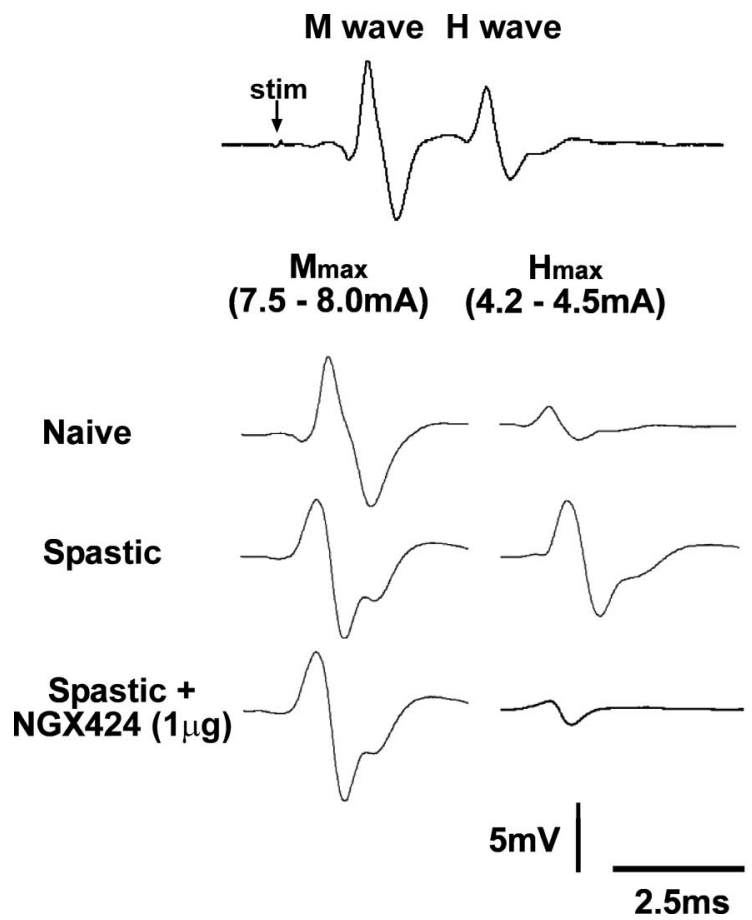

Figure 4. Intrathecal NGX424 significantly reversed the exaggerated H-reflex in spastic rats. The top represents a typical recording from a spastic rat with clear $\mathrm{M}$ and $\mathrm{H}$ waves present. Below, the left column shows a consistent $M$ wave $\left(M_{\text {max }}\right)$ amplitude in both naive and ischemic animals at stimulation intensities of $7.5-8.0 \mathrm{~mA}$. The right column shows the $\mathrm{H}$ wave elicited with stimulus intensities of 4.2-4.5 mA (i.e., $\mathrm{H}_{\max }$ ) in control and spastic animals and in the same spastic animal after intrathecal NGX424 $(1.0 \mu \mathrm{g})$ treatment. A clear suppression of the otherwise increased $H$ wave can be seen. This effect lasted for 100-120 min. Intrathecal saline (vehicle) had no significant effect on the stimulation threshold or the $\mathrm{M} / \mathrm{H}$-wave amplitudes (data not shown).

collected and frozen at $-70^{\circ} \mathrm{C}$ until immunoblotting. Protein concentration for each homogenate was determined using a BCA kit (Pierce, Rockford, IL). Equal amounts of protein $(67 \mu \mathrm{g})$ were loaded onto an $8-16 \%$ Tris-glycine gel for electrophoresis and then transferred to a nitrocellulose membrane. After blocking in 5\% nonfat dry milk in $0.1 \mathrm{M}$ Trisbuffered saline (TBS) $-0.1 \%$ Tween 20 (TBST), membranes were incubated with primary antibody (GluR1/2/3/4; see below) overnight on a shaker at $4^{\circ} \mathrm{C}$. Membranes were washed three times for $10 \mathrm{~min}$ with TBST and incubated for $1 \mathrm{~h}$ on a shaker at room temperature with either goat anti-mouse or goat anti-rabbit horseradish peroxidase-conjugated antibody (1:5000; Pierce). Equal protein loading was adjusted by normalizing all immunoblots against their respective $\beta$-actin levels. Briefly, once the GluR protein was detected, the membrane was gently stripped, blocked, and incubated with mouse anti- $\beta$-actin $(1: 5000,1 \mathrm{~h}$ at room temperature; Sigma), and developed as above. Chemiluminescent detection (Pierce) was used to visualize immunoreactive bands, and quantitative analysis of the bands was performed using ImageQuant TL (GE Healthcare, Piscataway, NJ).

Perfusion fixation and fluorescent immunohistochemistry. For histological analysis of spinal cord tissue, rats were anesthetized with pentobarbital (100 mg/kg, i.p.) and phenytoin ( $25 \mathrm{mg} / \mathrm{kg}$, i.p.) and transcardially perfused with $200 \mathrm{ml}$ of heparinized saline, followed by $250 \mathrm{ml}$ of $4 \%$ paraformaldehyde in $0.1 \mathrm{~m}$ PBS, pH 7.4. The spinal cords were dissected and postfixed in the same fixative overnight at $4^{\circ} \mathrm{C}$. After postfixation, 


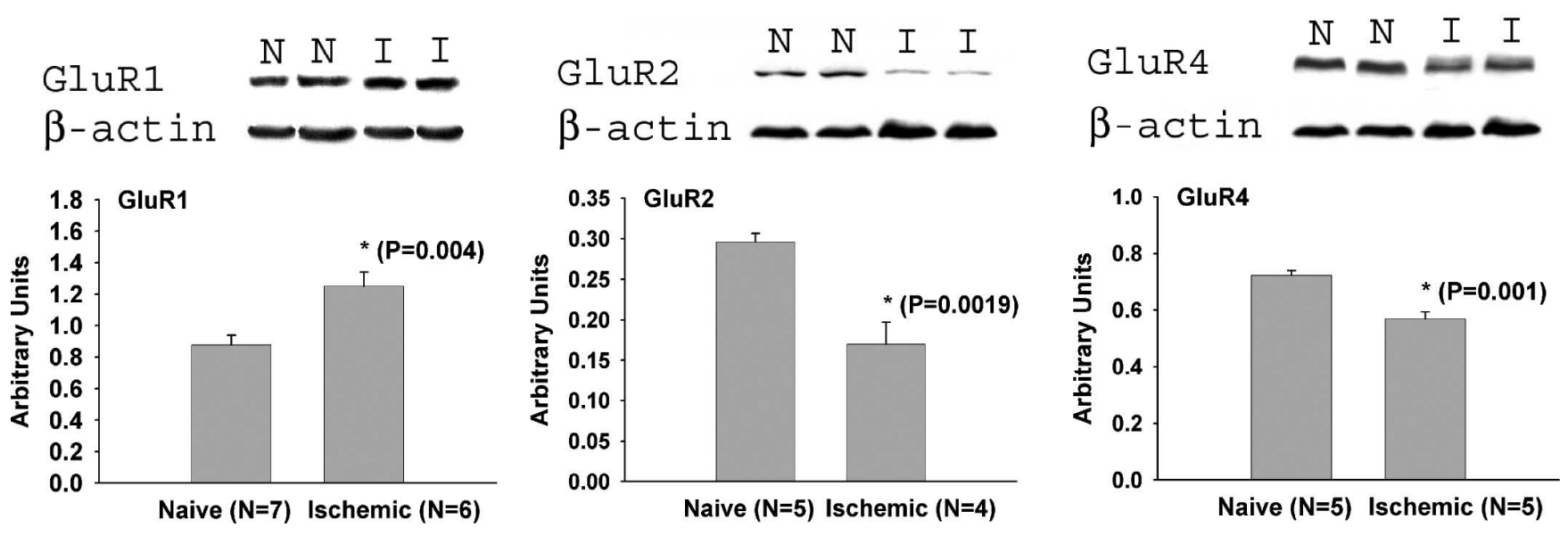

Figure 5. Spinal ischemic insult induces changes in total lumbar protein levels of GluR1, GluR2, and GluR4. Top of figure shows representative Western blot analysis results for each of these three AMPA receptor subunits (N, naïve; I, ischemic). Bottom section shows pooled data, indicating an increase in GluR1 subunit levels but decreased GluR2 and GluR4 levels compared with naive control animals. $p$ and $n$ values are listed; error bars represent the SEM.

tissue was cryoprotected in 30\% sucrose phosphate buffer. Transverse spinal cord sections $(10 \mu \mathrm{m})$ were then cut using a Leica (Bannockburn, IL) cryostat and mounted directly on slide glass; sections from naive and ischemic-injured spinal cord were mounted on each slide to ensure identical staining and allow proper comparison. For staining, slides were placed in PBS containing 5\% normal goat serum (NGS), $0.2 \%$ Triton $\mathrm{X}-100$ (TX) overnight at $4^{\circ} \mathrm{C}$ to block nonspecific protein activity. This was followed by a $2 \mathrm{~d}$ incubation at $4^{\circ} \mathrm{C}$ on a shaker with primary antibodies: rabbit anti-GluR1 (1:1000; Upstate, Charlottesville, VA), mouse anti-GluR2 (1:500; Chemicon, Temecula, CA), mouse anti-GluR3 (1: 500; Chemicon), rabbit anti-GluR4 (1:500; Chemicon), mouse antineuronal-specific nuclear protein (NeuN) (1:1000; Chemicon), biotinylated mouse anti-NeuN (1:1000; Chemicon), rabbit anti-glial fibrillary acidic protein (GFAP) (1:1000; Chemicon), and mouse anti-GFAP-cyanine 3 (Cy3) conjugate (1:500; Sigma).

After incubation with primary antibodies, sections were washed three times in PBS and incubated with secondary goat anti- rabbit or -mouse antibodies conjugated to a fluorescent marker (Alexa 488 or 594; 1:250; Invitrogen, Carlsbad, CA) or avidin-Cy3 (1:400; Sigma). All antibody preparations were made in PBS-TX-NGS. For general nuclear staining, $4^{\prime}, 6^{\prime}$-diamidino-2-phenylindole (1:250) was added to the secondary antibody solutions.

Standard control experiments for all antibodies used involved omission of primary antibody. To further test the specificity of the GluR1 antibody, preadsorption studies were performed. For this, GluR1 antibody (1:1000) was incubated with $1 \times 10^{-5} \mathrm{M}$ GluR1 control peptide (GluR1 primary antibody immunizing peptide; a generous gift from $\mathrm{Up}$ state) in PBS-TX-NGS overnight at $4^{\circ} \mathrm{C}$ on shaker. This solution was then used the following day as GluR1 primary antibody solution for staining. Identical staining, including double-labeling experiments (e.g., GluR1 plus GluR2 plus GluR1 control peptide), was performed at the same time but without the immunizing peptide to confirm other procedures were correct.

After staining, sections were dried at room temperature and covered with Prolong anti-fade medium (Invitrogen). Slides were analyzed using a Leica fluorescence microscope and captured with a digital camera [Orca-ER (Hamamatsu, Shizuoka, Japan) or microfire S99809 (Olympus Optical, Tokyo, Japan)]. Some slides were selected for confocal imaging using a Leica LCS SP2 confocal microscope (Leica, Bannockburn, IL). All images were processed by Adobe Photoshop CS (Adobe Systems, Mountain View, CA), with equal changes in brightness and contrast when applicable.

Immunohistochemistry with antigen unmasking. To visualize synaptic AMPA receptor subunits, some sections were pepsin treated (Watanabe et al., 1998; Nagy et al., 2004). For these experiments, $70 \mu \mathrm{m}$ vibratome sections were cut and stored in $0.3 \mathrm{~m} \mathrm{PBS}(0.1 \mathrm{~m}$ PBS with $0.3 \mathrm{M} \mathrm{NaCl})$. Sections were treated with pepsin ( $1 \mathrm{mg} / \mathrm{ml}$; P-7000; Sigma) in $0.2 \mathrm{M} \mathrm{HCl}$ for $10 \mathrm{~min}$ at $37^{\circ} \mathrm{C}$ and washed three times for $10 \mathrm{~min}$ with $0.3 \mathrm{M}$ PBS at room temperature. After $30 \mathrm{~min}$ in $50 \%$ ethanol, sections were again washed three times for $10 \mathrm{~min}$ with $0.3 \mathrm{M}$ PBS, placed in primary antibody solution (in $0.3 \mathrm{M}$ PBS- $-0.3 \% \mathrm{TX}$ ), and incubated $24 \mathrm{~h}$ on a shaker at $4^{\circ} \mathrm{C}$. Sections were then processed as described above.

Immunoelectron microscopy. Naive and experimental spinal cord sections, $50 \mu \mathrm{m}$ thick, were cut on a vibratome and cryoprotected with glycerol-dimethylsulfoxide mixture. After cryoprotection, the sections were frozen and thawed four times and treated with $1 \%$ sodium borohydrate. To reduce nonspecific binding, the sections were treated with $0.3 \%$ $\mathrm{H}_{2} \mathrm{O}_{2}-10 \%$ methanol in TBS (100 mm Tris- $\mathrm{HCl}$ and $150 \mathrm{~mm} \mathrm{NaCl}, \mathrm{pH}$ 7.6) and $3 \%$ NGS $-1 \%$ bovine serum albumin in TBS. Sections were reacted overnight with rabbit anti-GluR1 (1:500; Chemicon). Bound antibody was detected using biotinylated donkey anti-rabbit IgG (1:500; GE Healthcare, Little Chalfont, UK), the ABC Elite kit (Vector Laboratories, Burlingame, $\mathrm{CA}$ ), and diaminobenzidine (DAB) as the chromogen. After $\mathrm{DAB}$ detection, some sections were processed by an additional antibody labeling cycle using the same method and antibody as above. This staining strategy enhanced the signal-to-background ratio while the background labeling was kept to minimal. Immunoreacted sections were postfixed in buffered $2 \% \mathrm{OsO}_{4}$, rinsed and stained in $1 \%$ uranyl acetate, and then dehydrated and embedded in Epon. Ultrathin sections were contrasted with uranyl acetate and analyzed under a Zeiss EM-10 electron microscope operated at $60-80 \mathrm{kV}$. Electron microscopic negatives were scanned and processed by Adobe Photoshop CS2 (Adobe Systems).

Astrocyte culture and AMPA-stimulated glutamate release. Spinal cord astrocytes were isolated from lumbar spinal cords of postnatal day $0-1$ rat pups using Papain Dissociation System (Worthington, Lakewood, $\mathrm{NJ}$ ). After isolation astrocytes were cultured with DMEM-10\% fetal bovine serum (FBS) on Nunclon six-well plates. To purify astrocytes, mechanical shaking was used on day 7 after isolation. Astrocytes were then fed with fresh DMEM-10\% FBS every $3 \mathrm{~d}$ until confluent and were then passaged into 24-well plates. After passage, astrocytes were cultured for 3-5 more days before in vitro release experiments were initiated.

On the day of the release experiments, medium was replaced with 300 $\mu \mathrm{l} /$ well artificial CSF (ACSF) (in mm: $151.1 \mathrm{Na}^{+}, 2.6 \mathrm{~K}^{+}, 0.9 \mathrm{Mg}^{2+}, 1.3$ $\mathrm{Ca}^{2+}, 122.7 \mathrm{Cl}^{-}, 21.0 \mathrm{HCO}_{3}, 2.5 \mathrm{HPO}_{4}$, and 3.5 dextrose; bubbled for 15 min before the experiment with $95 \% \mathrm{O}_{2} / 5 \% \mathrm{CO}_{2}$ to adjust the final $\mathrm{pH}$ to 7.3). After $10 \mathrm{~min}$ in the incubator, a baseline sample $(25 \mu \mathrm{l})$ was collected from each well, immediately frozen on dry ice, and stored at $-70^{\circ} \mathrm{C}$ until analysis. AMPA was added to each well at varying concentrations $(1,10$, and $30 \mu \mathrm{M}$; each well received one concentration and was used only once), and the 24-well plate was placed back in the incubator for $10 \mathrm{~min}$, when another set of samples were collected and frozen. Antagonist studies were performed by adding the antagonist (NGX424, $1 \mu \mathrm{M}$ ) to the wells 10 min before adding AMPA. Each experiment was performed in four independent culture wells. Samples were analyzed for glutamate by 
HPLC (model HTEC 500; Eicom, Kyoto, Japan) using the E-ENZYMPAK enzymatic derivatization and the GU-GEL column with electrochemical detection.

In vitro immunohistochemistry. After release experiments were completed, cells were washed (three times for $10 \mathrm{~min}$ in PBS) and fixed for 30 min with $4 \%$ paraformaldehyde $/ 0.1 \%$ glutaraldehyde at room temperature. After washing (three times for $10 \mathrm{~min}$ in PBS), cells were incubated with primary antibodies recognizing GluR1, GFAP, or NeuN overnight at $4^{\circ} \mathrm{C}$. The following day, each well was washed (three times for $10 \mathrm{~min}$ in PBS), and appropriate secondary antibodies (Alexa 488 and 594; Invitrogen) were used for visualization. Images were captured with an Olympus Optical inverted microscope equipped with a digital camera (Hamamatsu).

Image analysis. Effect of GluR1 antisense/ missense on spinal cord GluR1-IR was analyzed by University of Texas Health Science Center at San Antonio ImageTool (3.0) using confocal microscope images captured using identical settings for each treatment group. Maximum pixel intensity in each field was normalized to $100 \%$, and the background was set to zero. The total area under the pixel intensity histogram was calculated for each field and two to three fields averaged for each section (using at least three sections per animal and three to four animals per group). To assess changes in individual motoneurons, similar analyses were performed using only outlined motor cells in the images (and normalizing for the analyzed area). Cell counts were done manually.

Data analysis. Muscle resistance results are presented as either applied resistance (g; grams force) or normalized as percentage of baseline resistance. All dose-response curves were calculated using area-under-the-curve analysis of the time course data. Statistical testing was performed using SigmaStat 2.03 for Windows (SPSS, Chicago, IL). Two-way comparisons were performed with Student's $t$ test. Multiple comparisons were performed using one-way ANOVA, followed by Student-Newman-Keuls test. All results are shown as mean \pm SEM. $p<$ 0.05 was considered to be statistically significant. For EMG analysis, the integrated signal was calculated from 20 averaged points and plotted.

\section{Results}

Selective loss of spinal interneurons after spinal ischemia

Immunofluorescence staining of lumbar spinal cord sections with NeuN antibody at 3-4 weeks after ischemia revealed bilateral loss of small- and medium-sized interneurons localized in lamina VII (data not shown), typical of transient ischemic insult and corresponds with the presence of functionally defined spasticity and rigidity (Marsala et al., 2004; Kakinohana et al., 2006).

\section{Transient spinal ischemia produced hindlimb spasticity and rigidity}

The majority of animals exposed to $10 \mathrm{~min}$ of spinal ischemia displayed progressive development of extensor type paraplegia 3-7 d after ischemia. In the same animals, ongoing motor activity was clearly present in the gastrocnemius muscle in which tonic EMG activity (indicative of rigidity) was measured with full-wave
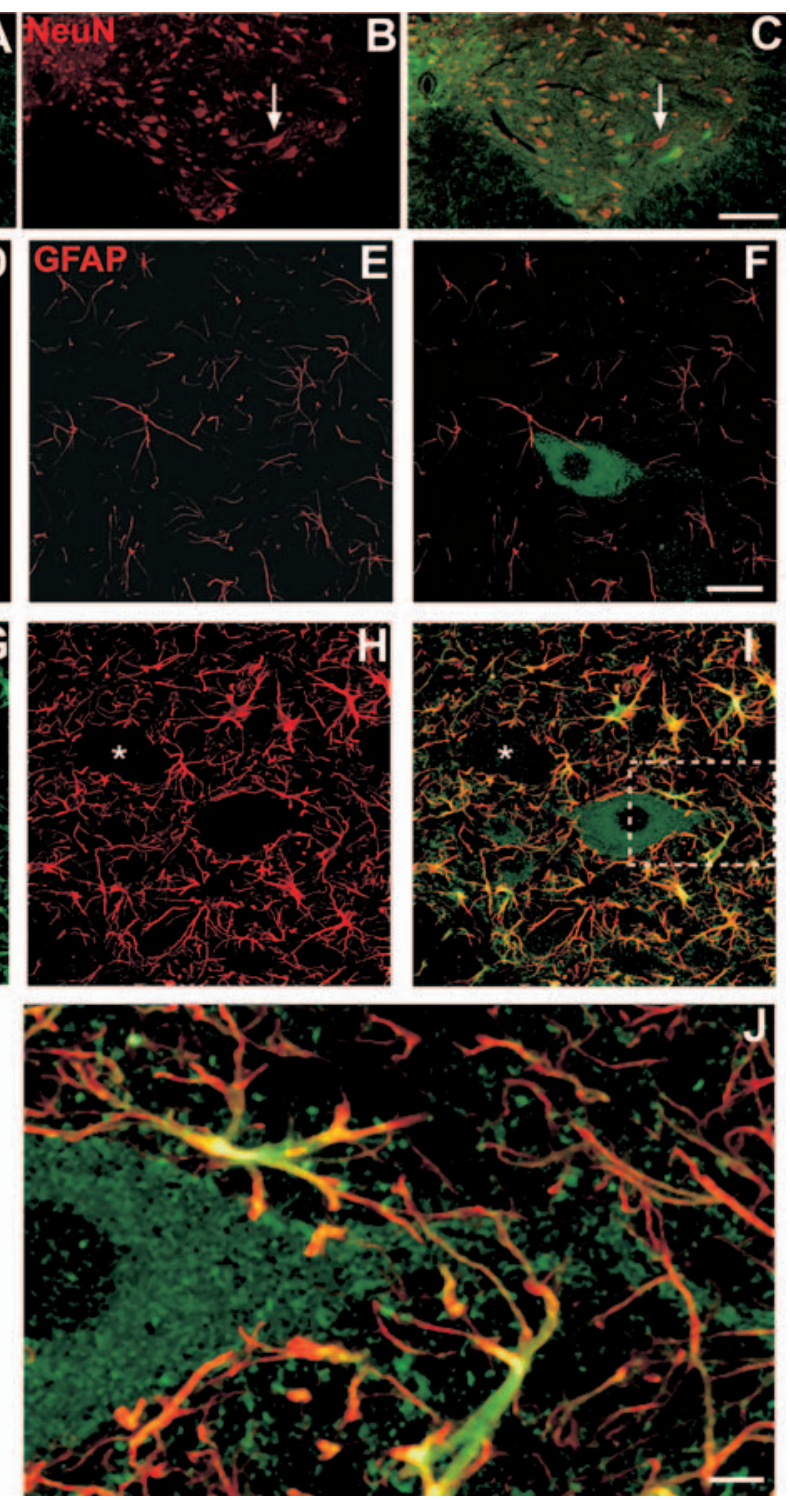

Figure 6. GluR1 immunoreactivity in the ventral horn of naive and ischemic-injured spinal cord sections. A-C, GluR1-positve neurons (green) can be seen in the ventral horn of naive tissue, whereas some nearby neurons are GluR1 negative (arrow). $\boldsymbol{D}-\boldsymbol{F}$ 列 ear-complete colocalization with GluR1-IR J Enlarged details taken from I (dashed box) showing GFAP/GluR1-positive astrocytes extending processes around adjacent motoneurons. Confocal images were constructed from 14 layers with z-separation of $0.5 \mu \mathrm{m}$. Scale bars: $\boldsymbol{A}-\boldsymbol{C}, 150 \mu \mathrm{m} ; \boldsymbol{D}-\mathbf{I}, 40 \mu \mathrm{m} ; \boldsymbol{J}, 10 \mu \mathrm{m}$.

amplitudes of $0.5-1.5 \mathrm{mV}$ (Fig. 1A). The majority of these animals also displayed continuous dorsal plantar flexion as well as flexion of paw digits (Fig. $1 E$ ). Measurement of PMR during ankle rotation $\left(40^{\circ} / 3 \mathrm{~s}\right)$ showed a significant increase in ischemicinjured animals compared with control (control, 0-25 g vs ischemic, 100-400 g), and this increase in PMR temporally correlated with increased EMG activity (consistent with the presence of spasticity) (Fig. 1A). Apart from hindlimb spasticity and rigidity, all animals exhibited normal grooming and feeding behavior, regular weight gain, and had normal bladder function.

\section{Effect of treatment on muscle rigidity}

Intrathecal injection of vehicle (saline) had no significant effect on tonic EMG activity (data not shown). In contrast, analysis of 


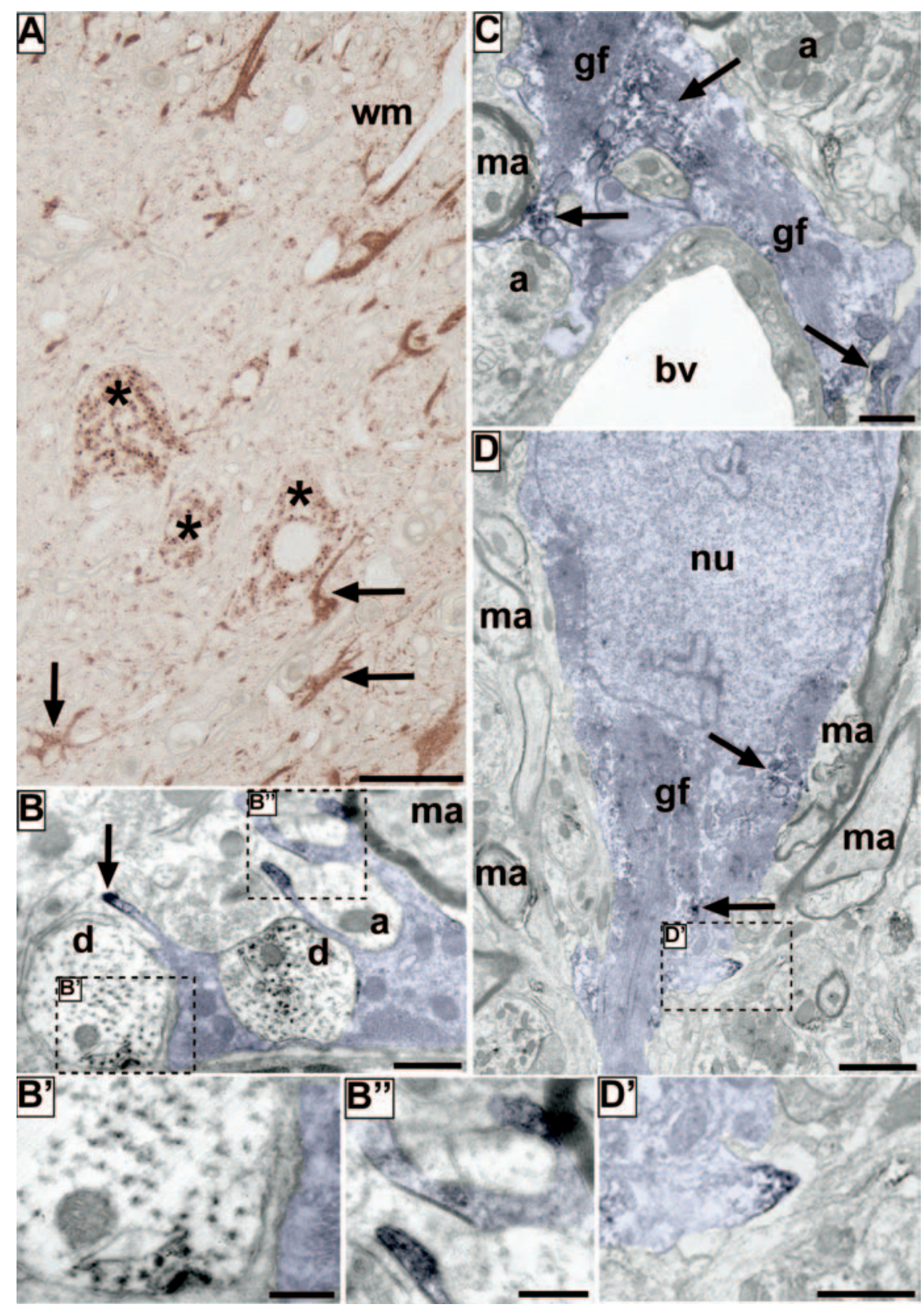

Figure 7. Electron microscopic analysis of reactive astrocytes showed GluR1 immunoreactivity in hypertrophic processes. $\boldsymbol{A}$, Bright-field image of semithin section shows several GluR1-immunoreactive motor neurons $\left({ }^{*}\right)$ and hypertrophic astrocytes (arrows) in the lateral motor group near the white matter border (wm). $\boldsymbol{B}$, Electron microscopic image of astrocyte process between several axons (a), a myelinated axon ( $\mathrm{ma}$ ), and dendrites (d). DAB reaction product appears concentrated in the neuronal dendrites $\left(\boldsymbol{B}^{\prime}\right)$ and in apical regions of the astrocyte processes (arrow and $\boldsymbol{B}^{\prime \prime}$ ). C, Perivascular astrocytes were also immunoreactive for GluR1 with reaction product found distributed throughout the glial filaments (gf; arrows) and close to blood vessels (bv). $D, A$ large hypertrophic astrocyte process with $\mathrm{DAB}$ reaction product found outside the cell nucleus $(\nu)$ and adjacent to the astrocyte outer membrane $\left(\boldsymbol{D}^{\prime}\right)$. Scale bars: $\boldsymbol{A}, 50 \mu \mathrm{m} ; \boldsymbol{B}, 250 \mathrm{~nm} ; \boldsymbol{B}^{\prime}, \boldsymbol{B}^{\prime \prime}, 100 \mathrm{~nm} ; \boldsymbol{C}, 1 \mu \mathrm{m} ; \boldsymbol{D}, 2 \mu \mathrm{m} ; \boldsymbol{D}^{\prime}, 1 \mu \mathrm{m}$.

the integrated EMG signal after intrathecal delivery of $1.0 \mu \mathrm{g}$ of NGX424 showed significant suppression of tonic EMG activity ( $43 \pm 6 \%$ of control; $n=4 ; p<0.05$ ) (Fig. 1 , compare $A, B$, tonic EMG; $D$, integrated EMG data). During the same period, clear relief of dorsal plantar flexion as well as flexion of the digits could be seen in the paw (Fig. 1, compare E, F), which was absent by $24 \mathrm{~h}$ after injection (Fig. $1 G$ ).

\section{Effect of NGX424 treatment on spasticity}

Although injection of intrathecal saline had no effect on PMR or EMG activity measured during ankle rotation, intrathecal injection of $0.1,0.3$, or $1.0 \mu \mathrm{g}$ of NGX424 significantly suppressed PMR as well as otherwise increased EMG activity (Fig. 1, compare $A, B$, ankle rotation). Addition of isoflurane anesthesia (2\%) almost completely blocked EMG activity and further reduced PMR (Fig. $1 C)$. Figure $2 A$ illustrates a representative experiment showing intrathecal vehicle injection (10 $\mu$ l of saline), followed by $1.0 \mu \mathrm{g}$ of NGX424. Onset of action was evident within 10 min of injection, whereas peak effect and duration of action were positively correlated with dose (Fig. 2 B). Dose-response analysis using area-under-the-curve data from the individual time courses produced a linear relationship over the range of $0.1-1.0 \mu \mathrm{g}$ (Fig. $2 C$ ) with an $\mathrm{ED}_{50}$ value of $0.44 \mu \mathrm{g}$ (0.33-0.58) and maximum reduction in PMR of $\sim 50 \%$ with the $1.0 \mu \mathrm{g}$ dose. Results from each dose were significantly different from each other, and the slope of the dose-response curve was statistically different from zero (slope, $-42.9 \pm$ $4.9 ; p<0.001)$. Similar results were obtained using peak-effect analysis (data not shown). Intrathecal administration of the AMPA/KA receptor antagonist CNQX $(10 \mu \mathrm{g})$ resulted in a similar reduction in PMR as obtained with $0.3 \mu \mathrm{g}$ of NGX424 (Fig. 2D), suggesting an $\sim 30$-fold difference in potencies. Systematic analysis of EMG activity after intrathecal NGX424 $(1.0 \mu \mathrm{g})$ showed a $25 \pm 4 \%$ reduction compared with predrug flexion values $(n=4 ; p<0.05)$ (Fig. $1 B, D$, after NGX424). The intrathecal doses presented in this study $(0.1$, 0.3 , and $1.0 \mu \mathrm{g}$ ) did not produce sedation or impair alertness in naive or spastic rats (Table 1). Drug-induced motor impairment in the hindlimbs was not assessed in spastic rats attributable to the paraplegic phenotype, but no effects were noted in upper limbs or upper torso in general. Hindlimb motor impairment was noted when intrathecal NGX424 was injected in naive animals, but effects were limited to caudal regions, consistent with a localized spinal effect after lumbar intrathecal injections and minimal rostral drug migration. Intrathecal doses of $3.0 \mu \mathrm{g}$ showed mild signs of decreased alertness, whereas doses of $10 \mu \mathrm{g}$ or higher produced severe sedation in most rats.

\section{Effect of NMDA receptor blockade on spasticity}

To delineate any contribution of NMDA receptors to the spasticity/rigidity in this model, changes in peripheral muscle resistance were examined in response to intrathecal AP-5 treatment. Intrathecal AP-5 $(5.0 \mu \mathrm{g})$ did not significantly alter muscle resistance up to $60 \mathrm{~min}$ after delivery (Fig. $2 \mathrm{D}$ ). 


\section{Effect of NGX424 treatment on motor evoked potentials}

In control animals, electrical stimulation of the motor cortex led to the appearance of MEP response measured in gastrocnemius muscle with full-wave amplitudes ranging from 2 to $5 \mathrm{mV}$. After ischemia, spastic animals showed a progressive increase $(\sim 25 \mathrm{mV})$ in MEP amplitudes (Fig. $3)$. In these animals, the intrathecal injection of saline had no significant effect. Intrathecal injection of $1.0 \mu \mathrm{g}$ of NGX424 completely blocked MEP (Fig. 3), with a time course similar to that seen with the PMR/EMG experiments.

Effect of NGX424 treatment on H-reflex In control animals, the stimulus threshold to elicit the H-reflex response was 3-3.5 $\mathrm{mA}$. In contrast, in animals with ischemic spasticity and rigidity, the H-reflex could be identified at stimulation intensities of $2-2.5 \mathrm{~mA}(p<0.05)$. Calculation of $\mathrm{H}_{\max } /$ $\mathrm{M}_{\max }$ ratio showed a significant increase in animals after ischemia (control, $0.22 \pm$ 0.04 ; ischemic, $0.60 \pm 0.07 ; p<0.01$ ). No significant differences in the $\mathrm{M}$-wave amplitude at specific stimulation intensities (0-10 mA, $0.5 \mathrm{~mA}$ increments) were seen between control and ischemic animals. Intrathecal administration of NGX424 (1.0 $\mu \mathrm{g})$ led to a significant decrease in $\mathrm{H}_{\max } /$ $M_{\max }$ ratio $(65 \pm 15 \%)$, with no significant effect on $\mathrm{M}$ wave (Fig. 4). This effect lasted for 100-120 min. Intrathecal saline had no significant effect on the stimulation threshold or $\mathrm{M} / \mathrm{H}$-wave amplitudes (data not shown).

\section{Changes in AMPA receptor subunit (GluR1-GluR4) expression after spinal cord ischemia}

\section{Western blot analysis}

Western blot analyses of AMPA receptor subunits in the control lumbar spinal cord revealed detectable levels of all four subunits. At 3-4 weeks after ischemia, GluR1 protein level increased $\sim 39 \%$, whereas GluR2 and GluR4 levels were reduced by 41 and $27 \%$ respectively (Fig. 5). Total changes in lumbar GluR3 levels as measured by immunoblotting did not reach statistical significance (data not shown).

\section{GluR1 staining}

Staining of transverse lumbar spinal cord sections taken from control sham-operated animals revealed GluR1-positive neurons throughout the gray matter, including dorsal horn and intermediate zone. GluR1-IR was also noted in a subpopulation of ventral $\alpha$-motoneurons (Fig. 6A-C) as well astrocytes. Thus, double labeling with GFAP and GluR1 antibody showed a weak GluR1 immunoreactivity in GFAP-positive astrocytes (Fig. 6D-F). After ischemia, numerous activated, hypertrophic astrocytes were found. Systematic quantification showed an average $2.4 \pm 0.3-$ fold more astrocytes in the ventral horn compared with control. GluR1 immunofluorescence was noted in $36 \pm 2 \%$ of ventral horn astrocytes after ischemia compared with $10 \pm 3 \%$ in control (Fig. 6G-I), consistent with the increase in protein level measured by Western blotting. GluR1-positive astrocytic processes extending toward ventral $\alpha$-motoneurons were also identified (Fig. $6 I, J$ ). No detectable differences in GluR1 expression in $\alpha$-motoneurons was seen between control and ischemic animals, in which in both groups GluR1-positive and -negative $\alpha$-motoneurons were identified with comparable regional distribution in the ventral horn (Fig. $6 D, G$ ).

Bright-field images from semithin sections of DAB-reacted tissue revealed clear GluR1 immunoreactivity in ventral $\alpha$-motoneurons and activated astrocytes (Fig. 7A). Electron microscopic images of ultrathin sections from the same area revealed $\mathrm{DAB}$ reaction product clustered near the outer membrane of astrocytes (Fig. $7 B, B^{\prime \prime}, D^{\prime}$ ), in some cases found in close proximity to axons and dendrites. The staining pattern noted in the astrocyte processes was remarkably similar to that found in dendrites (Fig. $7 B, B^{\prime}$ ). Reactive astrocytes also contained DAB reaction product throughout their soma, particularly within the glial filaments (Fig. 7C,D).

Sections previously treated with pepsin to expose the membrane-bound antigen showed a consistent presence of GluR1-IR on $\alpha$-motoneuron membranes but not in astrocytes (Fig. 8A, $B$ compared with non-pepsin-treated sections in Fig. $6 A, D, G)$ (Watanabe et al., 1998; Nagy et al., 2004).

\section{GluR2, GluR3, and GluR4 staining}

In control sections, GluR2 and GluR3 immunoreactivity was seen in numerous neurons throughout the gray matter as well as in astrocytes localized in both white and gray matter (Fig. $9 A, B, E, F)$. Three weeks after spinal ischemia, numerous GluR2and GluR3-positive neurons and hypertrophic astrocytes could be detected in the ventral horn (Fig. $9 C, D, G, H$ ), but a large 
Naive
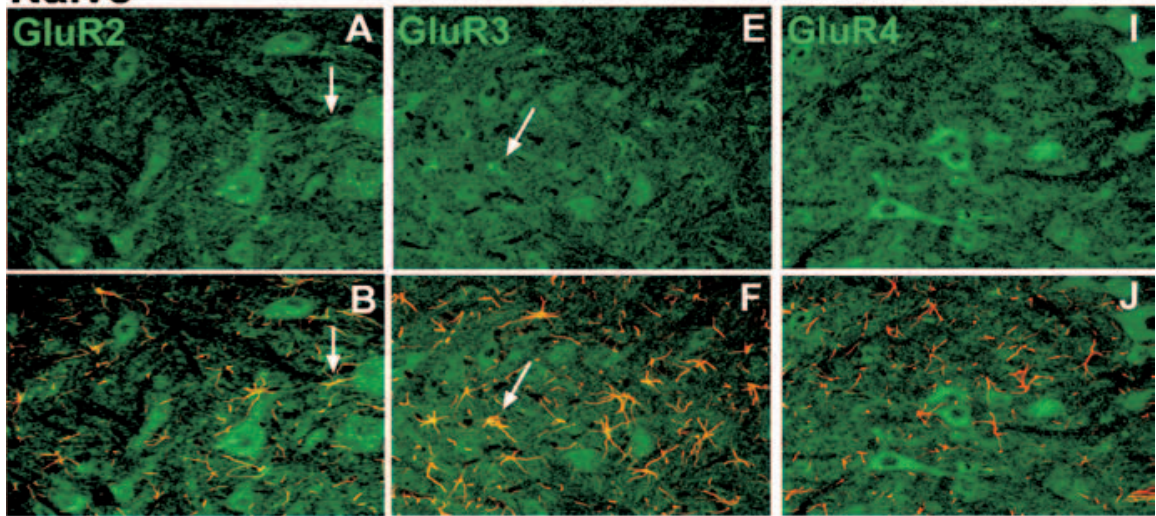

\section{Ischemic}
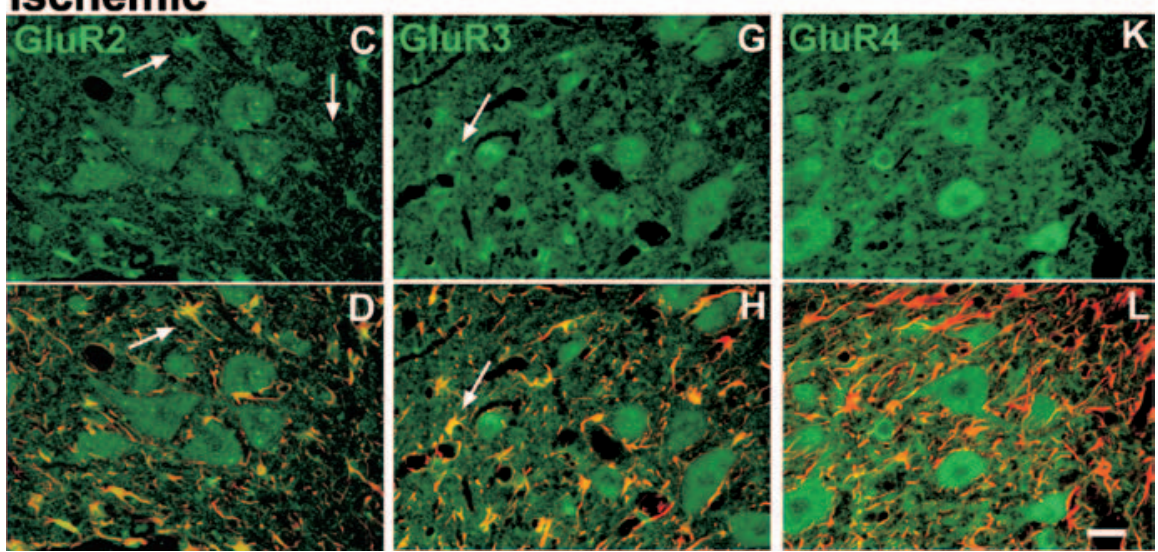

Figure 9. Immunohistochemistry showing GluR2-, GluR3-, and GluR4-IR in the ventral horn before and after spinal ischemia. $\boldsymbol{A}, \boldsymbol{B}$, Fluorescent microscope images showing GluR2-immunoreactive ventral horn cells and some GluR2-immunoreactive astrocytes before ischemia. C, D, After ischemia, strong expression of GluR2 can be seen in astrocytes (GFAP, red; colocalization shown as orange). GluR3-IR was also noted in ventral horn cells and astrocytes, before $(\boldsymbol{E}, \boldsymbol{F})$ and after $(\boldsymbol{G}, \boldsymbol{H})$ spinal ischemia. Strong GluR4-IR was evident in numerous ventral horn cells, but little appeared to colocalize with GFAP $(\boldsymbol{I}, \boldsymbol{J})$ in control tissue; similar results were seen for GluR4 after spinal ischemia $(\boldsymbol{K}, \boldsymbol{L})$. Scale bar, $50 \mu \mathrm{m}$.

population of immunoreactive neurons in the dorsal horn and intermediate zone were lost, consistent with a selective degeneration of these classes of neurons after spinal ischemia (Marsala et al., 2005). The neuronal staining pattern for the GluR4 subunit was similar as that for GluR3, except that fewer astrocytes showed colocalization with GluR4 in control tissue (Fig. 9I,J). After spinal ischemia, GluR4-positive neurons were detected in the ventral horn (Fig. $9 K, L$ ), but, like GluR2/3, a large number of GluR4positive neurons were lost in the ischemic-damaged regions. No marked change in astrocytic GluR4 expression was noted (Fig. $9 K, L)$.

\section{Specificity of GluR1-GluR4 antibody}

Immunohistochemistry control experiments supported specificity of the primary antibodies used in this study. Exclusion of any primary antibody resulted in low intensity, nonspecific fluorescence (data not shown). Similarly, preadsorption of the GluR1 antibody with the immunizing peptide used to generate the antibody completely blocked GluR1 (Fig. 8C,D) but not GluR2 (Fig. $8 D, E)$ immunoreactivity.

\section{Glutamate release from astrocyte cultures}

Pure astrocyte cultures were used to assess glutamate release from astrocytes and the efficacy of NGX424 to block AMPA-evoked glutamate release. After replacing the culture media with ACSF and a 10 min incubation, the basal glutamate concentration in each well was $2.9 \pm$ $0.3 \mu \mathrm{M}$. Addition of $1.0 \mu \mathrm{M}$ AMPA failed to evoke any change in bath glutamate levels, but incubation with $30 \mu \mathrm{M}$ AMPA increased bath glutamate concentration by $16.2 \pm 4.0 \%$ (Fig. $10 A)(n=4)$. Pretreatment with NGX424 $(1.0 \mu \mathrm{M})$ for $10 \mathrm{~min}$ before application of $30 \mu \mathrm{M}$ AMPA completely blocked any change in bath glutamate concentration (Fig. 10 A). Immunofluorescence staining of cultured astrocytes showed that $>95 \%$ of cells were GFAP-IR and $\sim 80 \%$ of astrocytes were GluR1-IR (Fig. 10B,C). No NeuNpositive neurons were seen in any of the cultures used (data not shown). Quantitative analysis of astrocyte cultures showed that there was on average 4000-6000 astrocytes per well. For comparison only, mixed neuron-glia cell cultures showed a similar distribution of GluR1-positive astrocytes (Fig. $10 D, E$ ).

\section{GluR1 antisense treatment}

Treatment of ischemic rats with identified spasticity and rigidity with intrathecal GluR1 antisense for $5 \mathrm{~d}$ resulted in a reduction of tonic gastrocnemius muscle EMG activity to $28 \pm 4 \%$ of baseline (preantisense levels). Ankle flexion-evoked EMG activity was decreased similarly to $37 \pm 7 \%$ of baseline, whereas hindlimb muscle resistance was reduced to $68 \pm 6 \%$ of baseline. Figure $11 A-E$ shows sample recordings from one animal and summary data for the group $(n=5)$. Missense treatment failed to alter EMG activity or muscle resistance (Fig. 11E). Confocal microscopy of spinal cord sections prepared from both treatment groups revealed a clear GluR1 downregulation in both neurons and reactive astrocytes (Fig. 12A-F). Densitometric analysis of GluR1-IR in lamina VIII showed an approximately threefold decrease in overall staining intensity (Fig. 12G). However, the most striking difference was noted in reactive astrocytes. After GluR1 antisense treatment, only $6 \pm 2 \%$ of ventral horn astrocytes were GFAP/GluR1 double immunoreactive, which is in sharp contrast to missense-treated animals in which $33 \pm 3 \%$ of GFAP-positive astrocytes were found to be GluR1 immunoreactive (Fig. 12 H). No change was found in the total number of GluR1immunoreactive motoneurons, but the intensity of staining in individual motoneurons was decreased by $38 \pm 11 \%$ (Fig. 12I).

\section{Discussion}

\section{NGX424 mechanism of action and systemic side effects}

Previous studies have demonstrated that NGX424 is a competitive AMPA/KA receptor antagonist, with high affinity for the GluR1-GluR4 AMPA receptor subunits and moderate affinity for GluR5 (Schoepp et al., 1991; Bleakman et al., 1996; Simmons et al., 1998). AMPA receptor subunits have been found on spinal $\alpha$-motoneurons as well as on presynaptic Ia afferents, consistent with their demonstrated role in motor function. For example, in vitro experiments revealed that (1) direct application of AMPA to 


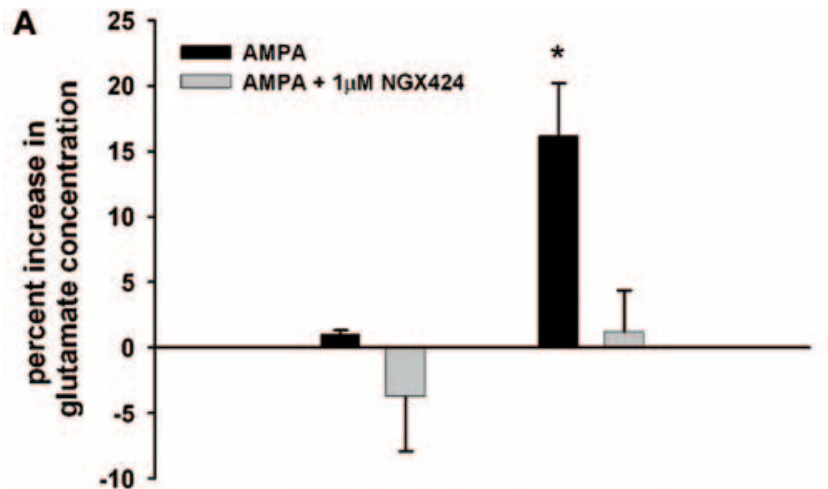

$1 \overline{\mu \mathrm{M} \text { AMPA }} 3 \overline{30 \mu \mathrm{M} \text { AMPA }}$

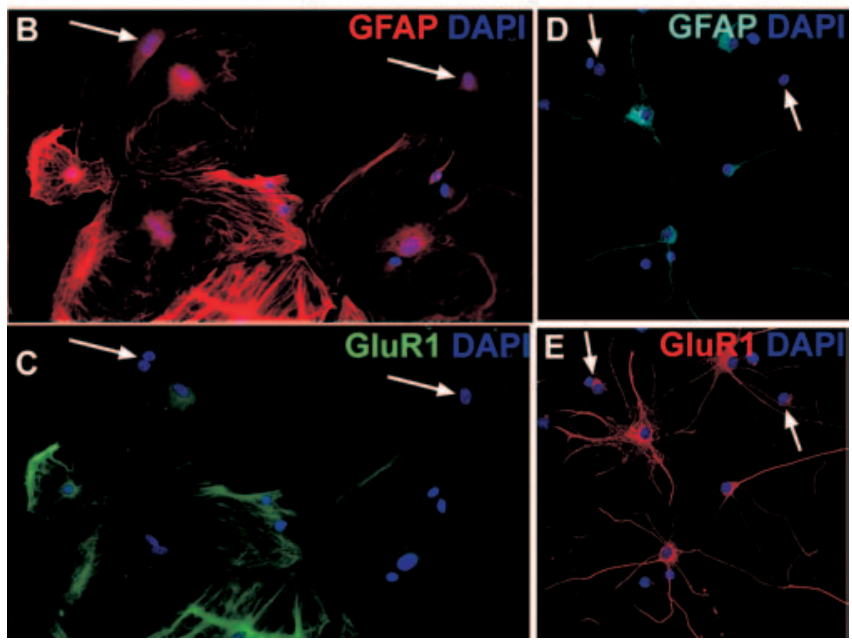

Figure 10. AMPA-evoked glutamate release from astrocytes in culture. $A$, Application of 1 $\mu \mathrm{M}$ AMPA to pure astrocyte cultures failed to evoke any significant change in the bath gluta-

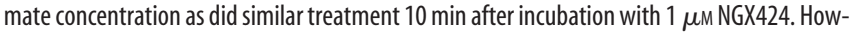
ever, $30 \mu$ M AMPA increased extracellular glutamate concentrations by $16.2 \pm 4.0 \%$, an effect that was completely blocked by pretreatment with $1 \mu \mathrm{m}$ NGX424. B, C, Astrocyte cultures fixed and immunostained after glutamate release experiments showed that nearly all cells were GFAP positive and a subpopulation showing GluR1-IR. Although the majority of GFAPimmunoreactive cells were also positive for GluR1, arrows show some examples in which astrocytes did not express GluR1. D, E, GluR1 immunostaining in mixed cultures showed similar staining pattern in some astrocytes and neurons (arrows indicate GFAP-negative cells that are likely neurons). DAPI, 4',6'-Diamidino-2-phenylindole.

motoneuron cultures resulted in significant acetylcholine release (Fontana et al., 2001), and (2) 2,3-dihydroxy-6-nitro-7-sulfonylbenzo $[f]$ quinoxaline (NBQX) or CNQX potently suppressed the monosynaptic reflex in the isolated spinal cord-tail preparation (Ault and Hildebrand, 1993; Pinco and Lev-Tov, 1993). In the intact animal (1) short-term (2 h) intrathecal infusion of AMPA produced reversible spastic paraplegia in the rat (Nakamura et al., 1994), (2) systemic or intrathecal NBQX suppressed spasticity in a genetic mutant rat model of spasticity (Turski and Stephens, 1993), and (3) intrathecal DNQX, but not AP-7, blocked the monosynaptic reflex in naive rats (Schwarz et al., 1995). These data are consistent with our current findings demonstrating a potent anti-spasticity/rigidity effect after NGX424 treatment but a lack of such effect after spinal NMDA receptor blockade using AP-5 doses reported to be antinociceptive (Hama et al., 2003; Jones and Sorkin, 2005).

In the present study, anti-spastic doses of NGX424 (up to 1.0 $\mu g$, i.t.) showed no detectable side effects, such as respiratory depression or general sedation. Von Bergen et al. (2002) reported that intrathecal delivery of $5 \mathrm{nmol}(1.5 \mu \mathrm{g})$ of NGX424 caused motor and sensory impairment in control animals, an observation consistent with the anti-spasticity and anti-rigidity effects seen in the present study (Von Bergen et al., 2002). With higher doses, general sedation was seen in both control and ischemic animals presumably because of sufficient rostral drug migration.

Changes in AMPA receptor subunit expression after ischemia In naive animals, protein and mRNA of the four AMPA receptor subunits have been found in several spinal cord and brain regions as well as DRG cells (for review, see Malenka, 2003). Identifying changes in the AMPA receptor subunit makeup after injury can be of importance because different combinations of subunits within the receptor complex alter the pore characteristics (for review, see Ozawa et al., 1998). Our data show a decrease in total GluR2 protein after spinal ischemia, which is in line with previous reports that showed reductions of both GluR2 mRNA and protein, including decreased mRNA in ventral motoneurons, after spinal contusion injury and cerebral ischemia (PellegriniGiampietro et al., 1992; Grossman et al., 1999, 2001). This reduction in total GluR2 likely reflects the loss of GluR2immunoreactive neurons demonstrated after spinal ischemia as well as a reduction in persisting neurons. The reduced GluR4 protein levels likely result from similar neuron loss. The reduced GluR2 expression in the surviving neurons is noteworthy because the presence of GluR2 in the receptor complex confers $\mathrm{Ca}^{2+}$ impermeability to the pore (Burnashev et al., 1992); thus, its loss increases $\mathrm{Ca}^{2+}$ influx, cell excitability, and delayed neuronal death (Pellegrini-Giampietro et al., 1992). Not only is it possible that the loss of GluR2 contributes to interneuronal cell death seen after spinal ischemic injury, as is also described for CA1 hippocampal neurons (Pellegrini-Giampietro et al., 1997), we also speculate that decreased GluR2 expression in excitatory interneurons or motoneurons likely potentiates clinical signs of spasticity and rigidity. Although a decrease in total GluR1 would be expected for similar reasons (i.e., interneuronal degeneration) as GluR2, Western blotting paradoxically shows that GluR1 is increased. In contrast to GluR2, the GluR1 subunit is expressed in a smaller population of interneurons in control naive animals. Accordingly, we believe that the loss of interneurons after ischemia has less impact on the overall GluR1 expression when analyzed by Western blot, and that the major contributor to the measured increase in GluR1 is derived from astrocytes.

In addition to changes in the functional properties of the AMPA receptor complex after ischemia, a change in expression of the individual subunits (such as decreased GluR2) can potentially affect the potency of an AMPA receptor antagonist if the drug possesses different affinities for each AMPA receptor subunit. NGX424 has highest affinity for GluR2 ( $K_{\mathrm{i}}$ value, $3.2 \pm 0.3 \mu \mathrm{M}$; lowest of all AMPA receptor subunits), followed closely by affinity for GluR1 ( $K_{\mathrm{i}}$ value, 9.2 $\pm 3.9 \mu \mathrm{M}$ ). Thus, it is conceivable that, if the anti-spasticity effect of NGX424 is primarily mediated by binding (at least in part) to GluR2, a reduction in drug efficacy could result from decreased GluR2 expression. However, doses used in the current study that were effective in various functional tests (e.g., H-reflex and muscle resistance) were similar to those used by Von Bergen et al. (2002) in control animals, suggesting minimal change in potency regardless of the overall change in the GluR expression pattern after spinal ischemic damage. The lack of diminished functional effect might be a result of upregulation of other subunits; that is, in contrast to a $41 \%$ reduction in GluR2 protein, GluR1 expression was increased by $39 \%$, and, because the affinity of NGX424 is very similar for each of these subunits, 

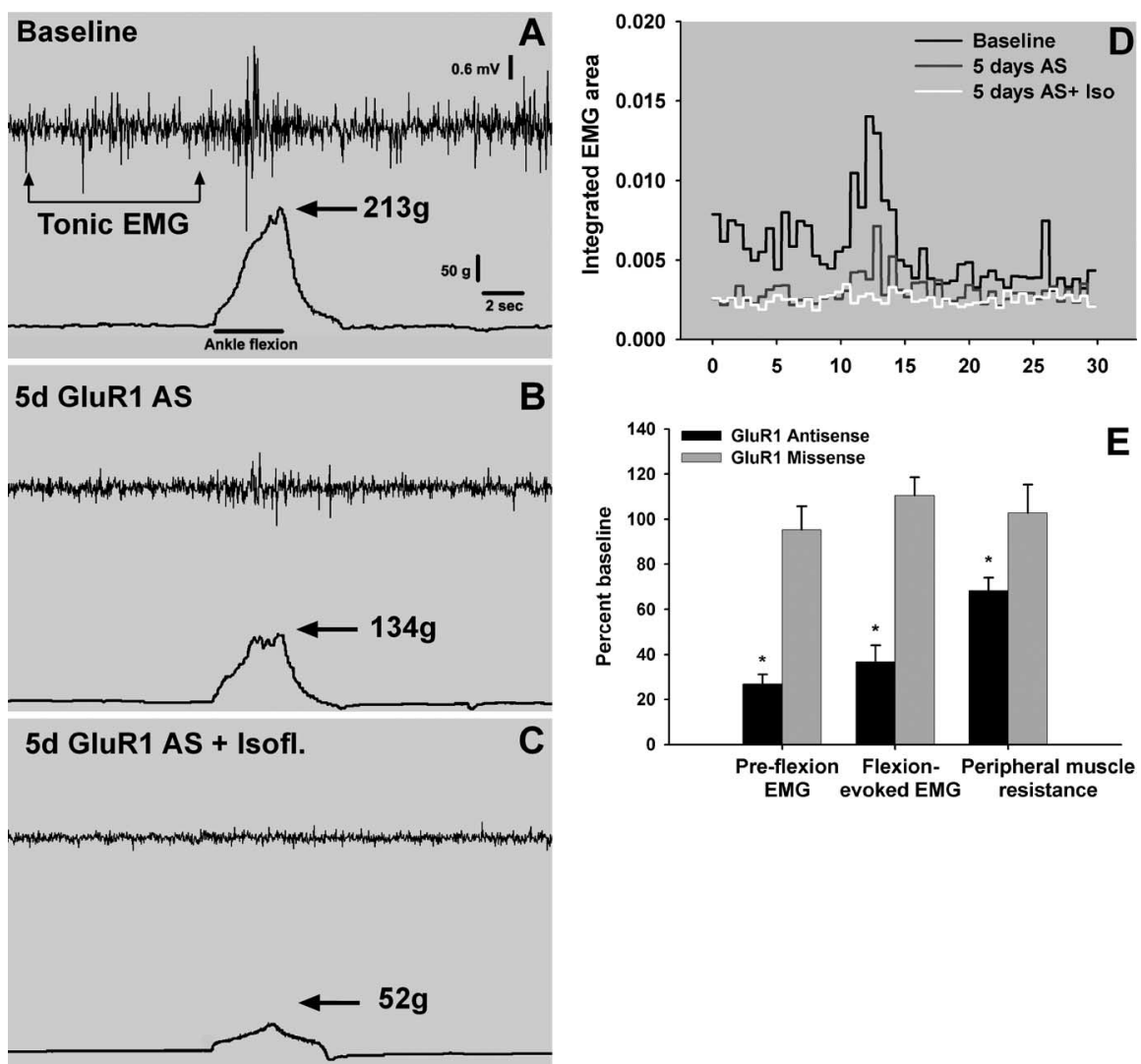

Figure 11. Intrathecal delivery of antisense oligonucleotides directed against GluR1 attenuated PMR and EMG activity and reduced spinal cord expression of GluR1 in motoneurons and reactive astrocytes. $A, E M G$ and PMR recorded in a spastic rat shows both tonic and flexion-evoked EMG activity and significant increase in PMR during ankle flexion. $\boldsymbol{B}$, Intrathecal GluR1 antisense (AS) treatment attenuated both EMG (tonic and evoked) and PMR. C, Addition of isoflurane (Isofl.) anesthesia (2\%) further reduced EMG and PMR. D, Integration analysis of the EMG data illustrates the efficacy of GluR1 antisense treatment. $\boldsymbol{E}$, Summary of data from animals that received either antisense or missense ( $n=4$ for each group).

increased GluR1 might compensate for any loss in GluR2 binding sites.

\section{Astrocytic GluR expression}

We emphasize that a principal finding in our analyses was the significant increase of GluR1 subunit expression in reactive astrocytes during chronic stages of ischemic spastic paraplegia. Gottlieb and Matute (1997) also reported GluR1immunoreactive hypertrophic astrocytes in the CA1 hippocampal region after transient forebrain ischemia (Gottlieb and Matute, 1997). Although the increased GluR1 expression reported in CA1 astrocytes appears to be less subtle than that noted in the current study, it is difficult to compare the absolute staining intensities of the two studies given the differences in tissue, model, and staining techniques.

Electron microscopic analysis revealed GluR1-IR within the astrocyte cell bodies and in some cases bound to the outer membrane of astrocyte processes adjacent to or within a few micrometers of neighboring axons/dendrites. Comparable EM images of GluR1 expression were described using GluR1 immunogold labeling in cerebellar Bergmann glial cells (Matsui et al., 2005). Interestingly, in our study, the staining pattern in astrocyte processes often resembled that found in neuronal dendrites in which $\mathrm{DAB}$ reaction product was also sometimes found clustered near the outer dendritic membrane, possibly suggesting a similar functional role for GluR1 in both cell types. It should also be noted that pepsin digestion of sections [reportedly exposing syn- aptically protected receptors (Nagy et al., 2004)] failed to show astrocytic GluR1 expression, suggesting these astrocytic receptors are not protected by the same synaptic proteins as are neuronal receptors and are therefore likely extrasynaptic. Indeed, most examples of astrocytic GluR1-IR found in our EM analyses appear to be extrasynaptic.

We propose that spinal ischemia results in increased astrocyte responsiveness to extrasynaptic glutamate (e.g., via AMPA receptors), resulting in secondary glutamate release that can maintain or even amplify ongoing activity in Ia afferents and $\alpha$-motoneurons contributing to clinical signs of spasticity and rigidity. Tian et al. (2005) offered an analogous connection between astrocytic glutamate release and epileptic seizure activity (Tian et al., 2005). There are several lines of evidence that support these hypotheses. Exposure of cultured rat astrocytes to NMDA or AMPA leads to a significant increase in intracellular $\mathrm{Ca}^{2+}$ as measured by fura-2, and this effect can be blocked by respective receptor antagonists (Hu et al., 2004). Using hippocampal slice preparations, Shelton and McCarthy (1999) reported increases in astrocytic $\left[\mathrm{Ca}^{2+}\right]_{\mathrm{i}}$ in response to application of glutamate alone, as well as metabotropic- or AMPA receptorselective agonists (Shelton and McCarthy, 1999). Subsequently, elevations of $\left[\mathrm{Ca}^{2+}\right]_{i}$ in astrocytes have been shown to induce glutamate release (Parpura et al., 1994; Pasti et al., 1997; Araque et al., 1998; Bezzi et al., 1998) that in turn evokes a slow inward current in nearby neurons and modulates action potential-evoked synaptic transmission between cultured hippocampal cells (Araque et al., 1998). Similarly, Fiacco and McCarthy (2004) demonstrated that a rise in astrocytic intracellular $\mathrm{Ca}^{2+}$ caused an increase in the frequency of AMPA receptor-mediated miniature EPSPs in nearby hippocampal neurons (Fiacco and McCarthy, 2004). These data are consistent with our in vitro experiments showing AMPA-evoked glutamate release using pure astrocyte cultures. Together, these data support a theorized positive-feedback system whereby glutamate released by astrocytes autoactivates glutamate receptors found on astrocyte membranes, further triggering $\mathrm{Ca}^{2+}$ oscillations and maintaining an increased glutamate concentration in the local milieu (Carmignoto, 2000; Parri et al., 2001; Larter and Craig, 2005).

An important role of AMPA receptor-expressing astrocytes in the evolution and maintenance of spasticity and rigidity was further supported by the potent anti-spasticity effect of spinal GluR1 antisense treatment, which also resulted in a dramatic decrease (sixfold) of GluR1-immunoreactive astrocytes. The reason for the preferential astrocytic response to GluR1 antisense treatment is unknown but may reflect differential uptake of the antisense oligonucleotides into astrocytes versus motor cells or different GluR1 protein turnover rates. Regardless, the simultaneous downregulation of astrocytic GluR1 and potent anti-spasticity effect after GluR1 antisense treatment suggests an important role for astrocytic AMPA receptors. However, because motoneuron 
GluR1 expression was also affected, its contribution to spasticity/rigidity must be acknowledged.

\section{Conclusion}

Data from the present study strongly suggests a role for spinal AMPA receptors in spasticity/rigidity. In addition, we report that, as part of the typical astrogliosis noted after CNS injury, transient spinal ischemia results in increased astrocytic AMPA receptor expression, and it is likely that activated astrocytes facilitate exaggerated $\alpha$-motoneuronal activity. Jointly, these data suggest that astrocytes represent novel cellular targets for spasticity/rigidity interventions, in which case the capacity to distinguish between neuronal and astrocytic AMPA receptors may have particular benefits (e.g., avoiding adverse effects associated with neuronal AMPA receptor blockade). Nevertheless, the current data provide clear evidence that spinal AMPA/KA receptor antagonism can represent a unique therapy in patients with chronic spasticity and rigidity with minimal systemic side effects.

\section{References}

Agrawal SK, Fehlings MG (1997) Role of NMDA and non-NMDA ionotropic glutamate receptors in traumatic spinal cord axonal injury. J Neurosci 17:1055-1063.

Araque A, Sanzgiri RP, Parpura V, Haydon PG (1998) Calcium elevation in astrocytes causes an NMDA receptor-dependent increase in the frequency of miniature synaptic currents in cultured hippocampal neurons. J Neurosci 18:6822-6829.

Ault B, Hildebrand LM (1993) Effects of excitatory amino acid receptor antagonists on a capsaicin-evoked nociceptive reflex: a comparison with morphine, clonidine and baclofen. Pain 52:341-349.

Beard S, Hunn A, Wight J (2003) Treatments for spasticity and pain in multiple sclerosis: a systematic review. Health Technol Assess 7:1-124.

Bezzi P, Carmignoto G, Pasti L, Vesce S, Rossi D, Rizzini BL, Pozzan T, Volterra A (1998) Prostaglandins stimulate calcium-dependent glutamate release in astrocytes. Nature 391:281-285.

Bleakman R, Schoepp DD, Ballyk B, Bufton H, Sharpe EF, Thomas K, Ornstein PL, Kamboj RK (1996) Pharmacological discrimination of GluR5 and GluR6 kainate receptor subtypes by $(3 \mathrm{~S}, 4 \mathrm{aR}, 6 \mathrm{R}, 8 \mathrm{aR})-6-[2-(1(2) \mathrm{H}-$ tetrazole-5-yl)ethyl]decahyd roisdoquinoline-3 carboxylic-acid. Mol Pharmacol 49:581-585.

Burnashev N, Monyer H, Seeburg PH, Sakmann B (1992) Divalent ion permeability of AMPA receptor channels is dominated by the edited form of a single subunit. Neuron 8:189-198.

Carmignoto G (2000) Reciprocal communication systems between astrocytes and neurones. Prog Neurobiol 62:561-581.

Dabney KW, Lipton GE, Miller F (1997) Cerebral palsy. Curr Opin Pediatr 9:81-88.

DietzV (2001) Gait disorder in spasticity and Parkinson's disease. Adv Neurol 87:143-154.

Faist M, Mazevet D, Dietz V, Pierrot-Deseilligny E (1994) A quantitative assessment of presynaptic inhibition of Ia afferents in spastics. Differences in hemiplegics and paraplegics. Brain 117:1449-1455.

Fiacco TA, McCarthy KD (2004) Intracellular astrocyte calcium waves in situ increase the frequency of spontaneous AMPA receptor currents in CA1 pyramidal neurons. J Neurosci 24:722-732.

Fontana G, Taccola G, Galante J, Salis S, Raiteri M (2001) AMPA-evoked
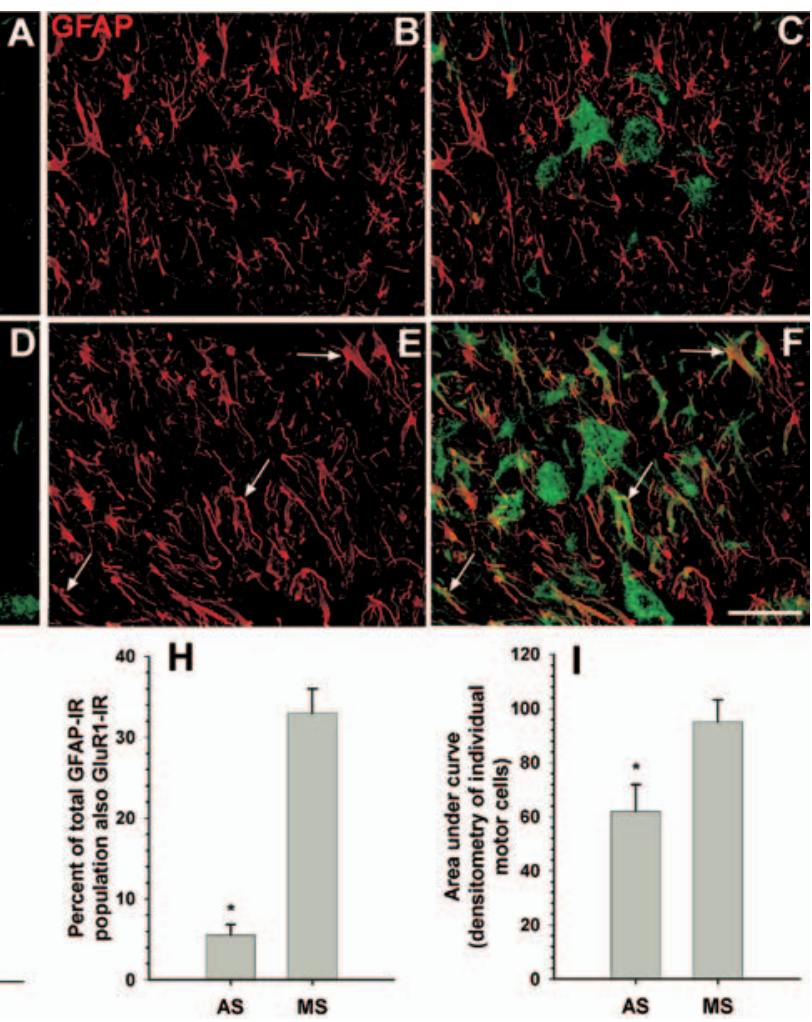

Figure 12. $\quad \boldsymbol{A}-\boldsymbol{C}$, GluR1 antisense treatment lead to a considerable reduction in GluR1-IR, particularly in reactive astrocytes reactive astrocytes were also GluR1-IR; antisense (AS) treatment reduced the number of astrocytes that were GluR1-IR to nearly $5 \%(\boldsymbol{H})$. Densitometry analysis of individual motoneurons also showed a significant reduction in staining $(\boldsymbol{I})$. Scale bar, $80 \mu \mathrm{m}$. hibition by GABA and glycine. Neuroscience 106:183-191.

Gottlieb M, Matute C (1997) Expression of ionotropic glutamate receptor subunits in glial cells of the hippocampal CA1 area following transient forebrain ischemia. J Cereb Blood Flow Metab 17:290-300.

Grossman SD, Wolfe BB, Yasuda RP, Wrathall JR (1999) Alterations in AMPA receptor subunit expression after experimental spinal cord contusion injury. J Neurosci 19:5711-5720.

Grossman SD, Rosenberg LJ, Wrathall JR (2001) Relationship of altered glutamate receptor subunit mRNA expression to acute cell loss after spinal cord contusion. Exp Neurol 168:283-289.

Hama A, Woon Lee J, Sagen J (2003) Differential efficacy of intrathecal NMDA receptor antagonists on inflammatory mechanical and thermal hyperalgesia in rats. Eur J Pharmacol 459:49-58.

Hefferan MP, Carter P, Haley M, Loomis CW (2003) Spinal nerve injury activates prostaglandin synthesis in the spinal cord that contributes to early maintenance of tactile allodynia. Pain 101:139-147.

$\mathrm{Hu}$ B, Sun SG, Tong ET (2004) NMDA and AMPA receptors mediate intracellular calcium increase in rat cortical astrocytes. Acta Pharmacol Sin 25:714-720.

Ivanhoe CB, Reistetter TA (2004) Spasticity: the misunderstood part of the upper motor neuron syndrome. Am J Phys Med Rehabil 83:S3-S9.

Jones TL, Sorkin LS (2005) Activated PKA and PKC, but not CaMKIIalpha, are required for AMPA/Kainate-mediated pain behavior in the thermal stimulus model. Pain 117:259-270.

Kakinohana O, Hefferan MP, Nakamura S, Kakinohana M, Galik J, Tomori Z, Marsala J, Yaksh TL, Marsala M (2006) Development of GABAsensitive spasticity and rigidity in rats after transient spinal cord ischemia: a qualitative and quantitative electrophysiological and histopathological study. Neuroscience 141:1569-1583.

Kinjoh K, Miyanohara M, Hefferan M, Marsala S, Kakinohana O, Yaksh T, Marsala M (2005) Stable downregulation of the GluR1 AMPA receptor 
subunit using lentiviral vector-mediated delivery of short hairpin RNA in primary cortical culture. Int J Neuroprotec Neuroregen 1:177-181.

Lance JW, Burke D, Gillies JD (1970) An electromyographic analysis of spasticity. Trans Am Neurol Assoc 95:272-274.

Larter R, Craig MG (2005) Glutamate-induced glutamate release: a proposed mechanism for calcium bursting in astrocytes. Chaos 15:047511.

Mailis A, Ashby P (1990) Alterations in group Ia projections to motoneurons following spinal lesions in humans. J Neurophysiol 64:637-647.

Malenka RC (2003) Synaptic plasticity and AMPA receptor trafficking. Ann NY Acad Sci 1003:1-11.

Marsala M, Kakinohana O, Yaksh TL, Tomori Z, Marsala S, Cizkova D (2004) Spinal implantation of hNT neurons and neuronal precursors: graft survival and functional effects in rats with ischemic spastic paraplegia. Eur J Neurosci 20:2401-2414.

Marsala M, Hefferan MP, Kakinohana O, Nakamura S, Marsala J, Tomori Z (2005) Measurement of peripheral muscle resistance in rats with chronic ischemia-induced paraplegia or morphine-induced rigidity using a semiautomated computer-controlled muscle resistance meter. J Neurotrauma 22:1348-1361.

Matsui K, Jahr CE, Rubio ME (2005) High-concentration rapid transients of glutamate mediate neural-glial communication via ectopic release. J Neurosci 25:7538-7547.

Matsushita A, Smith CM (1970) Spinal cord function in postischemic rigidity in the rat. Brain Res 19:395-410.

Maurice V, Allan HR, Raymond DA (2001) Adams and Victor's principles of neurology, Ed 7. Columbus, OH: McGraw-Hill.

Mazzocchio R, Rossi A (1989) Recurrent inhibition in human spinal spasticity. Ital J Neurol Sci 10:337-347.

Nagy GG, Al-Ayyan M, Andrew D, Fukaya M, Watanabe M, Todd AJ (2004) Widespread expression of the AMPA receptor GluR2 subunit at glutamatergic synapses in the rat spinal cord and phosphorylation of GluR1 in response to noxious stimulation revealed with an antigen-unmasking method. J Neurosci 24:5766-5777.

Nakamura R, Kamakura K, Kwak S (1994) Toxicity of AMPA, an excitatory amino acid, to rat spinal cord neurons under intrathecal administration (in Japanese). Rinsho Shinkeigaku 34:679-684.

Ozawa S, Kamiya H, Tsuzuki K (1998) Glutamate receptors in the mammalian central nervous system. Prog Neurobiol 54:581-618.

Parpura V, Basarsky TA, Liu F, Jeftinija K, Jeftinija S, Haydon PG (1994) Glutamate-mediated astrocyte-neuron signalling. Nature 369:744-747.

Parri HR, Gould TM, Crunelli V (2001) Spontaneous astrocytic $\mathrm{Ca}^{2+}$ oscillations in situ drive NMDAR-mediated neuronal excitation. Nat Neurosci 4:803-812.

Pasti L, Volterra A, Pozzan T, Carmignoto G (1997) Intracellular calcium oscillations in astrocytes: a highly plastic, bidirectional form of communication between neurons and astrocytes in situ. J Neurosci 17:7817-7830.

Pellegrini-Giampietro DE, Zukin RS, Bennett MV, Cho S, Pulsinelli WA (1992) Switch in glutamate receptor subunit gene expression in CA1 subfield of hippocampus following global ischemia in rats. Proc Natl Acad Sci USA 89:10499-10503.

Pellegrini-Giampietro DE, Gorter JA, Bennett MV, Zukin RS (1997) The GluR2 (GluR-B) hypothesis: $\mathrm{Ca}^{2+}$-permeable AMPA receptors in neurological disorders. Trends Neurosci 20:464-470.

Pinco M, Lev-Tov A (1993) Synaptic excitation of alpha-motoneurons by dorsal root afferents in the neonatal rat spinal cord. J Neurophysiol 70:406-417.

Salazar-Torres Jde J, Pandyan AD, Price CI, Davidson RI, Barnes MP, Johnson GR (2004) Does spasticity result from hyperactive stretch reflexes?
Preliminary findings from a stretch reflex characterization study. Disabil Rehabil 26:756-760.

Sanger TD, Delgado MR, Gaebler-Spira D, Hallett M, Mink JW (2003) Classification and definition of disorders causing hypertonia in childhood. Pediatrics 111:e89-e97.

Schoepp DD, Ornstein PL, Salhoff CR, Leander JD (1991) Neuroprotectant effects of LY274614, a structurally novel systemically active competitive NMDA receptor antagonist. J Neural Transm Gen Sect 85:131-143.

Schwarz M, Block F, Pergande G (1994) N-methyl-D-aspartate (NMDA)mediated muscle relaxant action of flupirtine in rats. NeuroReport 5:1981-1984.

Schwarz M, Schmitt T, Pergande G, Block F (1995) N-methyl-D-aspartate and alpha 2 -adrenergic mechanisms are involved in the depressant action of flupirtine on spinal reflexes in rats. Eur J Pharmacol 276:247-255.

Seifert G, Huttmann K, Schramm J, Steinhauser C (2004) Enhanced relative expression of glutamate receptor 1 flip AMPA receptor subunits in hippocampal astrocytes of epilepsy patients with Ammon's horn sclerosis. J Neurosci 24:1996-2003.

Seifert G, Schilling K, Steinhauser C (2006) Astrocyte dysfunction in neurological disorders: a molecular perspective. Nat Rev Neurosci 7:194-206.

Sheean G (2002) The pathophysiology of spasticity. Eur J Neurol 9 [Suppl 1]:3-9; discussion 53-61.

Shelton MK, McCarthy KD (1999) Mature hippocampal astrocytes exhibit functional metabotropic and ionotropic glutamate receptors in situ. Glia 26:1-11.

Simmons RM, Li DL, Hoo KH, Deverill M, Ornstein PL, Iyengar S (1998) Kainate GluR5 receptor subtype mediates the nociceptive response to formalin in the rat. Neuropharmacology 37:25-36.

Taira Y, Marsala M (1996) Effect of proximal arterial perfusion pressure on function, spinal cord blood flow, and histopathologic changes after increasing intervals of aortic occlusion in the rat. Stroke 27:1850-1858.

Tarlov IM (1967) Rigidity in man due to spinal interneuron loss. Arch Neurol 16:536-543.

Tawfik VL, Nutile-McMenemy N, Lacroix-Fralish ML, Deleo JA (2007) Efficacy of propentofylline, a glial modulating agent, on existing mechanical allodynia following peripheral nerve injury. Brain Behav Immun 21:238-246.

Taylor J, Munson J, Vierck Jr C (1999) Effects of dorsolateral spinal lesions on stretch reflex threshold and stiffness in awake cats. Eur J Neurosci 11:363-368.

Tian GF, Azmi H, Takano T, Xu Q, Peng W, Lin J, Oberheim N, Lou N, Wang X, Zielke HR, Kang J, Nedergaard M (2005) An astrocytic basis of epilepsy. Nat Med 11:973-981.

Turski L, Stephens DN (1993) Effect of the beta-carboline abecarnil on spinal reflexes in mice and on muscle tone in genetically spastic rats: a comparison with diazepam. J Pharmacol Exp Ther 267:1215-1220.

Von Bergen NH, Subieta A, Brennan TJ (2002) Effect of intrathecal nonNMDA EAA receptor antagonist LY293558 in rats: a new class of drugs for spinal anesthesia. Anesthesiology 97:177-182.

Watanabe M, Fukaya M, Sakimura K, Manabe T, Mishina M, Inoue Y (1998) Selective scarcity of NMDA receptor channel subunits in the stratum lucidum (mossy fibre-recipient layer) of the mouse hippocampal CA3 subfield. Eur J Neurosci 10:478-487.

Yaksh T, Rudy T (1976) Chronic catheterization of the spinal subarachnoid space. Physiol Behav 17:1031-1036.

Zhang Q, Hu B, Sun S, Tong E (2003) Induction of increased intracellular calcium in astrocytes by glutamate through activating NMDA and AMPA receptors. J Huazhong Univ Sci Technolog Med Sci 23:254-257. 